\title{
The Relationship Between Size of Living Space and Subjective Well-Being
}

\author{
Chris Foye ${ }^{1}$
}

Published online: 18 March 2016

(C) The Author(s) 2016. This article is published with open access at Springerlink.com

\begin{abstract}
Against a background of shrinking new homes and forebodings of "rabbit hutch Britain", the relationship between size of living space and subjective well-being has never been more topical in the UK. Using the British Household Panel Survey (BHPS) and fixed effects regressions, this paper is the first to examine this relationship comprehensively. Two pathways are proposed between space and subjective well-being. First, space facilitates values and activities. Second, space signals wealth which in turn influences social status. It is proposed that wealth is a more important determinant of status for men than women, and that pathway two is therefore gendered. Part one of the paper examines the effect of a change in number of rooms per person on housing satisfaction and subjective well-being in the BHPS as a whole. Despite having a similar effect on the housing satisfaction of both genders, an increase in living space has only a (weak) positive linear effect on the life satisfaction and mental health of men. This suggests that space affects subjective well-being through pathway two, status. Part two of the paper tracks the housing satisfaction and subjective well-being over time of those individuals who move for "larger accommodation". Consistent with various theories of adaptation, housing satisfaction increases in the year of the move; then decreases slightly before levelling out. Moving for "larger accommodation" has no positive impact on subjective well-being. Overall the results imply a weak positive relationship between size of living space and subjective wellbeing, but only for men.
\end{abstract}

Keywords Housing - Size of living space - Subjective well-being - Living conditions · Life satisfaction · Adaptation

Chris Foye

c.foye@ pgr.reading.ac.uk

1 Department of Real Estate and Planning, Henley Business School, University of Reading, Reading, UK 


\section{Introduction}

The relationship between size of living space and subjective well-being is commonly assumed to be positive. "Number of rooms per person" was used as an indicator of quality of life in both the OECD "Better Life Index" (2011) and the "European Quality of Life Survey" (2012). This relationship is particularly topical in the UK, where new homes are the smallest in Western Europe (Evans and Hartwich 2005). Concern has arisen because size of living space is important to people. Individuals who report a shortage of space are more likely to state a preference to move (Fujiwara 2014), and a shortage of space is the main reason for people in new homes wanting to make changes, or considering moving home (Robert-Hughes 2011).

There is quantitative evidence supporting an association between space and well-being (e.g. Reynolds 2005) but a striking absence of quantitative evidence supporting a causal relationship. Using the British Household Panel Study (BHPS), Pevalin et al. (2008) and Fujiwara (2014) both found housing problems to be detrimental to subjective well-being, yet neither found subjectively reported "shortage of space" to have an impact. This absence represents the rationale for examining the magnitude and direction of this relationship.

Shrinking of living spaces in the UK is generally attributed to the growing cost of developable land (Evans 1991). However, Tunstall (2015) and Dorling (2014) both argue that inequality also plays a role. Since the 1980's distribution of living space has become increasingly unequal. This could explain why the average new home has decreased in size. To test whether a more equal distribution of housing would make for a happier society, we must examine the shape of the relationship between space and subjective well-being. If an extra room brings more happiness to an individual in a 1-bedroom house than a 5-bedroom house, it follows that there is a utilitarian justification for a more equal distribution of space.

The value of size of living space as a metric of social well-being also depends on the dynamic relationship between size of living space and subjective well-being. Standard economic theory implies that any increase in subjective well-being caused by an increase in living space should be sustained over time. In contrast, adaptation theories variously imply that changes in living space lead to an initial impact on subjective well-being but that as individuals adapt, their well-being reverts to its previous level. Adaptation theories thus imply that space is a less important metric of societal well-being, as it has only a temporary effect on well-being. Together these diverse bodies of literature motivate the following research questions;

"What is the relationship between size of living space and subjective well-being in terms of magnitude, direction and shape?"

"Does the relationship differ over time?"

\section{Literature Review and Theory}

Our first task is to define subjective well-being. Subjective well-being has both an evaluative (cognitive/judgemental) component, and an experiential (emotional/affective) component (Pavot and Diener 1993). An individual eating a chocolate bar may be happy but dissatisfied with life, while a husband caring for his wife may be unhappy but satisfied 
with life. When assessed, these components are at least moderately correlated (Pavot and Diener 1993). In our analysis, we use indicators for both components and, in the absence of any literature to suggest otherwise, assume both components move together.

\subsection{Pathways from Size of Living Space to Subjective Well-Being}

Once there is sufficient space so as not to directly jeopardise physical health, this paper theorises two pathways through which size of living space is positively related to subjective well-being; through facilitating activities and values, and through status.

\subsubsection{Pathway 1: Facilitating Activities and Values}

An increase in living space (ceteris paribus) represents an increase in liberty. In the UK, for example, having friends round, sitting in peace and quiet and eating as a family are all activities limited by lack of space (Robert-Hughes 2011). By facilitating these activities, one would expect more space to lead to higher well-being. However, in a wider universal context, more space could be potentially damaging to well-being. Take the case of the Ghates in V.S. Naipaul's portrait of India;

"Mr Ghate was a high senior official. He had grown up in the mill area, in one room in a chattel, though it was open to him, as a man of position, to live in better accommodation in a better area. He had tried to do that some years before, but it had ended badly. His wife had suffered in the comparative seclusion and spaciousness of the self contained apartment they had moved to. This was more than moodiness, she had become seriously disturbed. Mr Ghate had moved back to a chattel, to the two rooms he had now, back to the sense of a surrounding crowd and the sounds of life all around him, and he was happy again" (p. 60)

In this case, the increased space (and new surroundings) added options for the Ghates in terms of facilitating more activities but took away the option of experiencing a vibrant homelife. In most cases, moving to larger accommodation is likely to involve a similar trade-off. Nonetheless, given that shortage of space is the subject of so many complaints in the UK (Robert-Hughes 2011), we would expect more space to lead to higher subjective well-being but with diminishing marginal effect. In other words, an increase from 1 room per person to 2 rooms per person is likely to facilitate more activities and values than an increase from 2 rooms per person to 3 rooms per person.

\subsubsection{Pathway 2: Status}

"A house may be large or small; as long as the neighbouring houses are likewise small, it satisfies all social requirements for a residence. But let there arise next to the little house a palace, and the little house shrinks to a hut" (Marx and Engels 1965)

The second pathway through which size of living space could influence subjective wellbeing is status. There is strong evidence of a causal relationship between status and subjective well-being. For example, Luttmer (2004) found individual life satisfaction to be negatively related to neighbours' income. See also Clark (2003) and Ferrer-i-Carbonell (2005). As Hirsch (2005) and Amartya Sen (1983) have pointed out, being concerned about status is rational as having high relative standing is a factor in the realization of numerous legitimate human objectives. One determinant of status is relative wealth. Relative wealth 
signifies one's ability (Frank 2007) and power over others (Csikszentmihalyi and Rochberg-Halton 1981). By engaging in conspicuous consumption (Veblen 1899) one can signal their wealth to others. A house is the largest and most expensive physical object most individuals consume, and size is one of the main determinants of house value. The size of one's house is therefore a visible indicator of wealth. However, because status is determined by relative wealth, what matters is not house size per se but relative house size. Frank (2007) found that most people state a preference for having a 3000 square foot house in a world where everyone else has a $2000 \mathrm{sq} f t$ house, as opposed to having a $4000 \mathrm{sq} f \mathrm{ft}$ house in a world where everyone else has a $6000 \mathrm{sq} \mathrm{ft}$ house. House size is therefore likely to be a positional good (Hirsch 2005; Frank 2007), whose utility value depends strongly on the consumption of others. In short, the relative size of one's house signals one's relative wealth, which in turn determines one's status or social rank, which is important to subjective well-being. Intuitively one would expect the relationship between size of living space and status to be more linear than pathway one. For a single person, moving from a 2 bedroom flat to a 3 bedroom flat is unlikely to facilitate many more activities but it will deliver status by virtue of the higher property value.

The policy implications of space influencing subjective well-being through pathway one and two are entirely different. Pathway one implies that an increase in average levels of living space would facilitate more household activities, and therefore increase societal well-being. Contrastingly, pathway two implies that individuals derive subjective wellbeing not from having more space in itself, but from having more space than other people. Thus increasing average levels of living space- through minimum space standards, for instance- is unlikely to have much effect on societal well-being. Instead, it is the distribution of living space that matters. According to the logic posited by Frank (2007) and Wilkinson and Pickett (2009) a more equal distribution of space would reduce the anxiety and sense of inferiority felt by those at the bottom and middle of the space distribution. So how do we distinguish between these pathways? One way is through the shape of the relationship. As noted, pathway two implies a more linear relationship between space and subjective well-being than pathway one. An additional way is through looking at how the relationship differs between genders.

There is substantial quantitative evidence to suggest that economic variables are more important to the status of men than women. Mayraz et al. (2009) found income comparisons to be a much better predictor of subjective well-being for men than women. Using econometric techniques on national panel datasets, Clark (2003), Clark et al. (2010) and Shields et al (2009) all found that the subjective well-being of unemployed men rises when faced with other people's unemployment at the regional level. None found any effect for women, apart from Clark (2003) who found a weak relationship. Furthermore, there is qualitative evidence that housing means more to men as a symbol of economic status than it does to women, who instead emphasise the home as a source of social status (Seeley et al. 1956; Rainwater 1966); and that men use objective terms to describe their homes, whereas women use more subjective terms (Gutmann 1965; Carlson 1971). All of the above suggests that, as an indicator of wealth, size of living space will matter more for the status of men than women. Consequently, pathway two should be stronger for men than women. There does not appear to be any literature to suggest that pathway one will be gendered once employment status and hours spent doing housework are controlled for. Therefore, if pathway two is present, we would expect size of living space to have a larger effect on the subjective well-being of men than women. 


\subsection{The Dynamic Aspect of the Relationship}

In the above literature review we discussed the direction, shape and magnitude of the relationship between size of living space and subjective well-being, and how these may differ according to (1) gender and (2) the pathways through which space affects subjective well-being. It is also important to know whether the relationship varies over time. According to standard economic theory, any increase in subjective well-being in the year after an increase in living space should be sustained over time, ceteris paribus. However, several studies have found that increases in housing and life satisfaction associated with moving house diminish over time, in a process which can be loosely defined as adaptation. Using Australian Panel Data, Frijters et al. (2011) found a positive effect of moving house (for all reasons) on life satisfaction but this effect lasted for 6 months only. Nakazato et al. (2011) examined the effect of moving for housing related reasons on the life satisfaction and housing satisfaction of 3658 participants in the German Socio-Economic Panel. In this scenario, moving house led to an increase in housing satisfaction but this was only partially sustained over the 5 years post-move. They found no effect on life satisfaction. Findlay and Nowok (2012) examined the trajectories of different domain satisfaction judgements after internal migration in the BHPS and similarly found housing satisfaction to take a downward post-move trajectory. The exception is Nowok et al. (2013), who found no evidence of adaptation in life satisfaction judgements. Again using the BHPS, they found that moving house (for any reason) was preceded by a period when individuals experienced a significant decline in life satisfaction. Moving house brought life satisfaction back to initial levels where they remained for the next 5 years (and perhaps longer). Their findings are therefore more consistent with standard economic theory.

The post-move downward trajectories of housing satisfaction and subjective well-being are consistent with adaptation theory (or set point theory), which contends that individuals have stable levels of subjective well-being shaped by genetics and personality. Deviations from the set-points may occur but their effects are usually transitory. However, as Nakazato et al. (2011) point out, adaptation theory is limited as it does not explain why these effects are transitory. There are two explanations-as follows- for why the increase in housing satisfaction after an improvement in living conditions is not sustained.

First, according to the aspiration spiral theory (Stutzer, 2004), after improving their living conditions, individuals could simply shift their expectations upwards; "now I have a 3 bedroom house, I want a 4 bedroom house." (Nakazato et al. 2011). Housing satisfaction judgements are generally thought to be constructed by individuals according to how their current housing situation relates to their preferred housing situation (Galster and Hesser 1981). For alternative theories of housing satisfaction, see Jansen (2014). According to this logic, an increase in living space will initially close the gap between one's preferred housing situation and reality, leading to an initial increase in housing satisfaction. But over time this gap will re-emerge causing any uplift in housing satisfaction to diminish. While housing preferences can be influenced by "relevant others" (Vera-Toscano and AtecaAmestoy 2008), theoretically the aspiration spiral theory need not involve social comparisons.

The second explanation for the post-move decrease in housing satisfaction is distinction bias (Hsee and Zhang 2004). In the year after moving to larger accommodation, individuals view their new house in direct comparison to their old house in a joint evaluation, so space is particularly salient. Over time, however, the new house will be viewed in isolation in a separate evaluation. Because space is not a naturally salient housing 
characteristic (i.e. it is not intrusive or unpredictable), its salience will decrease, and housing satisfaction judgements will diminish accordingly.

Housing satisfaction is not an indicator of subjective well-being itself. But according to the theoretical model of Van Praag et al. (2003), life satisfaction judgements are a function of different domain satisfaction judgements. Thus housing conditions affect housing satisfaction, which in turn affects life satisfaction. Because subjective well-being is a function of housing satisfaction, it should take a similar (although smoother) trajectory over time i.e. decrease before the move; increase in the year after the move; and decrease thereafter.

However, it may be that space influences subjective well-being independently of housing satisfaction. According to the hedonic treadmill theory, novel stimuli are more likely to lead to positive/negative affect as they are more likely to draw attention (Schimmack 2001; Wilson and Gilbert 2008). Initially more space will lead to an increase in positive affect, which will be reflected in higher experiential and evaluative well-being (Schimmack et al. 2002b). Over time, however, the novelty will wear off and subjective well-being will return to its previous levels. The hedonic treadmill theory does not predict adaptation in housing satisfaction judgements as these should not be influenced by positive/negative affect (Nakazato et al. 2011).

Alternatively, the influence of housing satisfaction judgements on subjective well-being may change throughout the moving process. It is in the interest of an individual's subjective well-being to place more emphasis on those life domains that most satisfy them. This is formally demonstrated by Bradford and Dolan (2010), in what they define as the global adaptive utility model. According to their model, the importance of housing should increase when levels of housing satisfaction increase, and decrease when housing satisfaction decreases. Therefore decreases in housing satisfaction should have little influence on life satisfaction judgements. Contrastingly, increases in housing satisfaction should be amplified in life satisfaction judgements.

Summarising, the existing literature predicts that size of living space will be positively related to subjective well-being and housing satisfaction. Pathway one implies the relationship will have diminishing marginal utility, whereas pathway two implies a more linear relationship. The literature on gender suggests that if pathway two exists, space should have a larger impact on men's subjective well-being. In terms of the dynamic relationship, distinction bias and aspiration spiral theory both imply that any increase in housing satisfaction associated with moving to larger accommodation will diminish post-move. According to Van Praag et al. (2003), subjective well-being should take a similar, although smoother, trajectory to housing satisfaction. In contrast, the global adaptive utility model and the hedonic treadmill theory both imply that subjective well-being will take a different trajectory to housing satisfaction. It is therefore important that we look at the effect of space on subjective well-being, and housing satisfaction separately.

\section{Data and Methodology}

There are two parts to the analysis. The first uses fixed effect regressions to identify how changes in number of rooms per person affects housing satisfaction and subjective wellbeing. The second examines the dynamic housing satisfaction and subjective well-being of those individuals who move to subjectively larger accommodation. For both parts, data is used from the British Household Panel Survey (BHPS) covering the period 1991-2008, including booster samples. The data used in this paper were extracted using the Add-On 
package PanelWhiz v4.0 (Oct 2012) for Stata. PanelWhiz was written by Dr. John P. Haisken-DeNew (john@panelwhiz.eu). The PanelWhiz generated DO file to retrieve the GSOEP data used here and any Panelwhiz Plugins are available upon request. Any data or computational errors in this paper are my own. Haisken-DeNew and Hahn (2010) describe PanelWhiz in detail.

To capture the evaluative component of subjective well-being, we use life satisfaction. Life satisfaction judgements correlate well with other people's views, behavioural data, brain activity and objective characteristics such as rates of depression (Layard 2005). Life satisfaction is measured using responses to the question of "How dissatisfied or satisfied are you with your life overall?", with responses on a scale of 1-7, where 1 signifies completely dissatisfied and 7 signifies completely satisfied. The experiential component of subjective well-being is proxied for using the General Health Questionnaire (GHQ). The GHQ is widely used in medical, psychological, and sociological research, and is considered to be a robust indicator of the individual's psychological state (Clark 2003). The GHQ asks individuals (via a self-completion questionnaire) how often they are experiencing certain feelings (e.g. happiness, strain, depression, lack of confidence) in relation to their usual state; "Not at all", "No more than usual", "Rather more than usual", and "Much more than usual". The Caseness version of the GHQ score is used, which counts the number of questions for which the response is in one of the two 'low subjective well-being' categories. Higher scores therefore indicate lower levels of subjective well-being. For ease of interpretation, the scales are reversed (i.e. $12=0 \ldots, 0=12$ ) after which the majority of respondents record a score of 12. Clark and Georgellis (2013) found trajectories of GHQ and Life Satisfaction to be very similar after life events (e.g. widowhood, marriage, unemployment). Housing satisfaction is evaluated using responses to the question; "How dissatisfied or satisfied are you with.........Your house/flat", with responses again on a scale of 1-7. Both housing satisfaction and life satisfaction were included every year from 1996 onwards with the exception of 2001. GHQ was included in every year.

For part one of the analysis, which is concerned with examining the magnitude, direction and shape of the relationship, a fixed effects model is adopted. The two indicators of subjective well-being and housing satisfaction are rotated as dependent variables, and separate regressions are run for males and females. Thus part one consists of a total of six regressions. Space is measured using rooms per person (number of rooms excluding kitchen and bathrooms/household size). We assume that, on average, when an individual reports an increase (or decrease) in rooms per person, this represents an increase (or decrease) in overall living space. The descriptive statistics support this case. In the BHPS sample, there is a negative correlation $(-0.26)$ between rooms per person and an individual reporting a shortage of space. Of those individuals who report moving for larger accommodation (5 year sample), $83 \%$ report an increase in number of rooms, and only $6 \%$ report a decrease.

Number of persons in the household is also controlled for separately. Therefore, the coefficients on 'rooms per person' indicate the effect of size of living space, keeping household size constant. Other control variables include variables that have been found to influence subjective well-being in the past; housing and environmental variables besides space e.g. damp; hypothesised costs associated with larger accommodation such as time spent commuting and doing housework. Furthermore, this study is the first to examine the effect of housing conditions on subjective well-being while controlling for "neighbourhood effects'. If we were to find a positive relationship between rooms per person and subjective well-being, it could be argued that this relationship is actually driven by neighbourhood effects i.e. increases (or decreases) in living space are associated with moving to a better 
(or worse) area- in terms of crime rates, schools, green areas etc. and it is these neighbourhood variables which explain the positive relationship between size of living space and subjective well-being. By including multiple deprivation statistics at the lower level super output area (SOA) - each of which contain approximately 1500 people according to figures from 2004 (ODPM 2004)—we can control for these potentially confounding neighbourhood effects. Because these statistics are not comparable across UK nations, part one of the analysis is limited to England. All control variables are listed and categorised in "Appendix 1". For all regressions conducted, standard errors are clustered at the individual level to account for any serial correlation.

In order to test for a linear relationship, all models are first tested with only 'rooms per person'. Then a quadratic interaction term is introduced (rooms per person squared) to test for non-linearity e.g. diminishing marginal utility. Results from the two specifications (with and without interaction term) are compared by examining the coefficient on 'rooms per person'. If this coefficient is more statistically significant with the quadratic term, than without, or the quadratic term itself is statistically significant, the relationship is deemed non-linear.

Part two of the analysis examines the dynamic aspect of the relationship. More specifically, it assesses the movement over time of subjective well-being and housing satisfaction, for individuals who move house and cite "larger accommodation" as their reason for moving. This yields a smaller sample size than part one that is less representative of the population because only certain types of individuals can, or want to, move to larger accommodation. The benefits are threefold. First, we can track the housing satisfaction and subjective well-being for movers over time. Second, the context surrounding the change in living space is more uniform, meaning we can more accurately identify spurious influences on subjective well-being. Third, we can test whether the effects of space on well-being are asymmetrical. For example, in part one, an increase in space may have a positive effect on subjective well-being, but a decrease in space may have no effect. By looking only at upsizers we may uncover a positive effect that is offset in part one.

In part two, a series of appropriate 'year relative to move dummies' are included in a fixed-effects regression to examine how the time relative to a move affects housing satisfaction and subjective well-being. This model has been used extensively for different life events (e.g. Clark and Georgellis 2013; Nowok et al. 2013). A broadly similar set of controls is used with a few exceptions (see "Appendix 1"). Because all of the sample moved house within nation states, it does not matter (for the interpretation of the coefficients of interest) that multiple deprivation statistics are not comparable across nation states. Therefore, in the second part of the analysis, individuals from throughout UK are included. Neighbourhood effects are controlled for, but only those which are available across UK (see "Appendix 1"). When GHQ was used as a dependent variable in part two, the results suggested multi-collinearity. Age was identified as the source. Therefore, all part two regressions are conducted without age as a control.

To maximise sample size, and the length of time over which adaptation is tested for, two overlapping samples are selected. To be included in either sample, an individual must have been observed in the same property 1-2 and 0-1 years before the move and have been observed in a different property $0-1$ years after the move. When individuals reported a change of address, they were asked: "Did you move for reasons that were wholly or partly to do with your own job, or employment opportunities?" Next, all movers were asked; "What were your (other) main reasons for moving?" to which they could reply with up to two reasons. For an individual to be included in either sample, their first reason 0-1 years 
after moving had to be "Larger Accommodation" (only $20 \%$ of respondents gave a second reason or cited employment reasons).

If an individual observation was missing or unknown in any of the periods $>2$ years post-move (as was the case for approximately $10 \%$ of individuals in the 5 year sample and $20 \%$ of the 7 year sample), it was reasonably assumed that they had not moved provided they fulfilled two criteria; they reported being in the same lower layer SOA (about $80 \%$ of

Table 1 Part One Results

\begin{tabular}{|c|c|c|c|c|c|c|}
\hline \multirow[t]{2}{*}{ Variables } & \multicolumn{2}{|l|}{ Housing_sat } & \multicolumn{2}{|l|}{ Life_sat } & \multicolumn{2}{|c|}{ GHQ_caseness } \\
\hline & Males & Females & Males & Females & Males & Females \\
\hline \multirow[t]{2}{*}{ rooms_pp } & $0.544 * * *$ & $0.464 * * *$ & $0.0431 * *$ & 0.014 & $0.110 * *$ & $-0.319 * *$ \\
\hline & -0.076 & -0.075 & -0.019 & -0.020 & -0.052 & -0.138 \\
\hline \multirow[t]{2}{*}{ rooms_pp_sq } & $-0.0747 * * *$ & $-0.0591 * * *$ & & & $0.0450 *$ & \\
\hline & -0.012 & -0.013 & & & & -0.024 \\
\hline \multirow[t]{2}{*}{ mover } & $0.350 * * *$ & $0.349 * * *$ & $0.0822 * * *$ & $0.0772 * * *$ & 0.076 & 0.078 \\
\hline & -0.033 & -0.032 & -0.024 & -0.024 & -0.057 & -0.067 \\
\hline \multirow[t]{2}{*}{ Household size } & 0.036 & -0.002 & -0.013 & $-0.0438 * *$ & 0.001 & $-0.0820 *$ \\
\hline & -0.026 & -0.024 & -0.019 & -0.017 & -0.046 & -0.046 \\
\hline \multirow[t]{2}{*}{ house_value } & $2.04 \mathrm{e}-07 * * *$ & $1.52 \mathrm{e}-07 * *$ & $4.94 \mathrm{E}-09$ & $4.27 \mathrm{E}-08$ & $4.36 \mathrm{E}-08$ & $9.65 \mathrm{E}-08$ \\
\hline & 0 & 0 & 0 & 0 & 0 & 0 \\
\hline \multirow[t]{2}{*}{ housing_costs } & $0.00022 * * *$ & $0.000321 * * *$ & $2.74 \mathrm{E}-05$ & $-1.57 \mathrm{E}-05$ & $-6.92 \mathrm{E}-05$ & $-9.59 \mathrm{E}-05$ \\
\hline & $-4.63 \mathrm{E}-05$ & $-5.38 \mathrm{E}-05$ & $-3.97 \mathrm{E}-05$ & $-3.71 \mathrm{E}-05$ & $-1.00 \mathrm{E}-04$ & -0.00013 \\
\hline \multirow[t]{2}{*}{ Garden } & $0.164 * * *$ & $0.173 * * *$ & 0.0323 & 0.0519 & -0.0728 & 0.0277 \\
\hline & -0.056 & -0.057 & -0.0394 & -0.0429 & -0.0917 & -0.106 \\
\hline \multirow[t]{2}{*}{ neighbour_noise } & $-0.144 * * *$ & $-0.200 * * *$ & -0.00549 & -0.0374 & -0.0631 & -0.0776 \\
\hline & -0.0328 & -0.0327 & -0.0259 & -0.0244 & -0.0606 & -0.0669 \\
\hline \multirow[t]{2}{*}{ street_noise } & $-0.0804 * * *$ & $-0.137 * * *$ & -0.0169 & -0.0363 & -0.0329 & -0.0803 \\
\hline & -0.0282 & -0.0286 & -0.0217 & -0.0222 & -0.0526 & -0.0576 \\
\hline \multirow[t]{2}{*}{ no_light } & $-0.154 * * *$ & $-0.172 * * *$ & -0.0321 & -0.0494 & $-0.179 * *$ & -0.0513 \\
\hline & -0.0447 & -0.044 & -0.0327 & -0.0354 & -0.0779 & -0.0885 \\
\hline \multirow[t]{2}{*}{ poor_heating } & -0.0922 & $-0.209 * * *$ & 0.011 & -0.0264 & -0.0404 & -0.044 \\
\hline & -0.0621 & -0.0569 & -0.0488 & -0.0441 & -0.107 & -0.111 \\
\hline \multirow[t]{2}{*}{ condensation } & $-0.0685^{* *}$ & $-0.104 * * *$ & -0.0143 & -0.0124 & -0.0165 & 0.00565 \\
\hline & -0.0319 & -0.0325 & -0.0249 & -0.0249 & -0.0601 & -0.0677 \\
\hline \multirow[t]{2}{*}{ damp_walls } & $-0.221 * * *$ & $-0.219 * * *$ & -0.00651 & $-0.0750 * *$ & 0.0533 & $-0.216^{* *}$ \\
\hline & -0.0388 & -0.0409 & -0.0296 & -0.0311 & -0.077 & -0.0844 \\
\hline \multirow[t]{2}{*}{ Rot } & $-0.131 * * *$ & $-0.197 * * *$ & -0.0302 & 0.000245 & $-0.123^{*}$ & 0.0376 \\
\hline & -0.0406 & -0.0407 & -0.029 & -0.0299 & -0.0742 & -0.0871 \\
\hline \multirow[t]{2}{*}{ Roof } & -0.0196 & -0.0662 & -0.0483 & 0.0416 & -0.0203 & 0.0766 \\
\hline & -0.0469 & -0.0527 & -0.0385 & -0.0406 & -0.0929 & -0.111 \\
\hline Observations & 25,905 & 29,050 & 25,888 & 28,939 & 28,862 & 32,343 \\
\hline R-squared & 0.064 & 0.071 & 0.036 & 0.028 & 0.055 & 0.042 \\
\hline Number of pid & 5460 & 5862 & 5467 & 5861 & 5551 & 5944 \\
\hline
\end{tabular}

$p$ value $*<0.1 ; * *<0.05 ; * * *<0.01$ 
moves in both samples were across lower layer SOA's) and they reported being in a broadly similar type of accommodation. To be included in the first (larger) 5 year sample, they must have been observed in, or reasonably assumed to have been in, the same larger property in 2 out of 3 of the years post-move. To be included in the second (smaller) 7 year sample, they must have been observed in, or reasonably assumed to have been in, the same larger property in 4 out of 5 of the years post-move. If individuals moved numerous times (in the BHPS) for larger accommodation, only their most recent move for larger accommodation is selected.

In both samples the vast majority $(>75 \%)$ of the sample are mortgage holders while $10-15 \%$ are public renters. There are very few private renters, presumably because the selection criteria require immobility before and after the move. For both samples, the median age is $33 / 34$ and the mean household income is approximately $£ 30,000$, which makes it significantly older $(+10$ years) and wealthier $(+£ 7000)$ than the BHPS sample as a whole. For the 5 year sample, the median distance moved was $1.3 \mathrm{~km}$ and $77 \%$ of moves were less than $5 \mathrm{~km}$, so on average moving is unlikely to have involved the disruption of social networks beyond those situated within the neighbourhood.

On the 5 year sample(s), the model below is adopted;

$$
S \ddot{W} B_{i t}=\beta \ddot{X}_{i t}+\theta_{-1} M_{-1, i t}+\theta_{0} M_{0, i t}+\theta_{1} M_{1, i t}+\theta_{2} M_{2, i t}+\ddot{\varepsilon}_{i t}
$$

Here, $S \ddot{W} B_{i t}$ stands for deviations from the individual mean of housing satisfaction or subjective well-being for a particular individual, $\mathrm{i}$, at a certain time, $\mathrm{t}$. $\mathrm{X}$ is a vector of control variables listed in "Appendix 1". Most importantly, there are four dummy variables indicating the year relative to moving house that the individual is observed in. Thus $M_{-1, i t}$, is a dummy variable that takes on the value of 1 if the individual is observed up to 1 year before the move, and 0 if it is not. The other three duration dummy variables operate in the same way. In all cases, the omitted dummy variable and thus the reference category for all individuals is $1-2$ years before the move $\left(M_{-2, i t}\right)$. On the 7 year sample, the same regression model is used, the only difference being an extra two dummy duration variables $\theta_{3} M_{3, i t}$ and $\theta_{4} M_{4, i t}$.

\section{Results}

\subsection{Part One}

A fixed effects regression is concerned with within individual changes; the changes in the value of a (dependent/independent) variable that the same individual reports from one year to the next. The results in Table 1 thus show the relationship between within individual changes in individual living space and within individual changes in housing satisfaction, life satisfaction and GHQ Caseness (for full results see "Appendix 2"). The sample is split according to gender. In interpreting the coefficients for both parts one and two, a one tail $t$ test is used for coefficients whose sign is consistent with prior hypotheses $(p<0.1)$, while a two tail $t$ test is used for coefficients whose sign is the opposite of that hypothesised or where no hypotheses exist $(p<0.05)$. Space aside, only a few housing variables influence life satisfaction or GHQ caseness. Poor light and rot both have a negative effect on male GHQ Caseness. Damp walls have a negative effect on both components of female subjective well-being. Almost all housing variables have an impact on housing satisfaction. 
For both males and females, rooms per person is positively related to housing satisfaction, but with diminishing marginal effect; up to a certain point (3.9 rooms per person for males and 3.6 for females), space is positively related to housing satisfaction but then the effect wears off. Space is more important to the housing satisfaction of men than women, but only slightly. In contrast, the relationship between space and broader subjective well-being is linear and distinctly gendered. For women, space has no effect on life satisfaction, and when we introduce a quadratic term space has a negative effect on GHQ caseness. ${ }^{1}$ For males, space is positively and linearly related to both aspects of subjective well-being, but the relationships are weak. For a single man, an increase in the number of rooms from 1 to 2 (excluding kitchens and bathrooms) increases life satisfaction by $0.043(p<0.05)$. Compared to the effect of major life events, this effect is small. For instance, in the year after marriage, males experience an increase in life satisfaction of $0.235(p<0.01)$ (Clark and Georgellis 2012). In terms of housing, Fujiwara (2014) used the BHPS and found that damp and neighbour noise were associated with a decrease in life satisfaction of 0.05 . Turning to experiential wellbeing, an increase in one room per person leads to an increase in male GHQ Caseness of 0.11 $(p<0.05)$, which is approximately half of that reported by males in the year after marriage $(0.21 ; p<0.1)$ (Clark and Georgellis 2012).

In summary, although size of living space has a similar effect on the housing satisfaction of men and women, space only has a (weak) positive effect on the subjective wellbeing of men.

\subsection{Part Two}

Part two tracked the housing satisfaction and subjective well-being of individuals before and after moving to subjectively larger accommodation. The descriptive statistics of the 5 and 7 year samples can be seen below in Table 2 .

In line with the sample requirements - that all individuals must be observed in the 2 years pre-move and first year post-move- the number of observations stays constant in the first 3 years before decreasing. The median rooms per person for the whole BHPS sample is 1.66. As can be seen in Table 2, individuals upsize to accommodation that is approximately the population average. The move clearly has the intended effect initially, with the proportion of respondents reporting a shortage of space dropping from 66 to $8 \%$ ( 5 year sample), but over the next 4 years the proportion reporting a shortage of space more than doubles (see 7 year sample). Individuals also move to a better neighbourhood (median multiple deprivation score for 5 year sample in $\mathrm{M}-1=15.3$; $\mathrm{M} 0=11.9$ ).

The findings for housing satisfaction are concurrent with adaptation, and can be seen in Table 3. For full results, see "Appendix 3". In the year before the move, individuals report a decrease in housing satisfaction, prompting them to move to larger accommodation. In the year after the move, housing satisfaction rises considerably, and is significantly higher than in the reference year (1-2 years pre-move). In the following years, however, increases in housing satisfaction diminish. In both samples, post-move increases in housing satisfaction (relative to $\mathrm{M}-1$ ) diminish by about $30 \%$ over the 3 years post-move. The 7 years sample shows that they stabilise from then on. Despite adaptation, levels of housing satisfaction are still significantly higher $4-5$ years after the move than they were 1-2 years before. It could be that those individuals who dropped out of the sample postmove were less satisfied with their accommodation than those who stayed, leading to post-

\footnotetext{
${ }^{1}$ One hypothesis for this result may be that, like Mrs Ghate, women suffer more from the comparative social isolation associated with larger living spaces.
} 
Table 2 Description of part two samples

\begin{tabular}{|c|c|c|c|c|c|c|}
\hline \multirow[t]{2}{*}{ Sample } & \multicolumn{2}{|c|}{$\begin{array}{l}\text { Number of observations } \\
\text { in sample }\end{array}$} & \multicolumn{2}{|c|}{$\begin{array}{l}\text { Median rooms per } \\
\text { person }\end{array}$} & \multicolumn{2}{|c|}{$\begin{array}{l}\% \text { Reporting space } \\
\text { shortage }\end{array}$} \\
\hline & 5 year & 7 year & 5 year & 7 year & 5 year & 7 year \\
\hline $1-2$ years pre-move $(\mathrm{M}-2)$ & 978 & 638 & 1.4 & 1.33 & 52 & 54 \\
\hline $0-1$ years pre-move $(\mathrm{M}-1)$ & 978 & 638 & 1.25 & 1.25 & 66 & 68 \\
\hline $0-1$ years post-move $(\mathrm{M} 0)$ & 978 & 638 & 1.63 & 1.63 & 8 & 8 \\
\hline 1-2 years post-move (M1) & 901 & 602 & 1.63 & 1.63 & 12 & 12 \\
\hline 2-3 years post-move (M2) & 775 & 613 & 1.6 & 1.5 & 16 & 17 \\
\hline 3-4 years post-move $(\mathrm{M} 3)$ & 0 & 587 & N/A & 1.5 & N/A & 20 \\
\hline 4-5 years post-move (M4) & 0 & 515 & N/A & 1.5 & N/A & 19 \\
\hline
\end{tabular}

Table 3 The effect of moving to larger accommodation over time

\begin{tabular}{|c|c|c|c|c|c|c|}
\hline \multirow[t]{2}{*}{ Variables } & \multicolumn{2}{|c|}{ Housing satisfaction } & \multicolumn{2}{|c|}{ Life satisfaction } & \multicolumn{2}{|c|}{ GHQ caseness } \\
\hline & 5 year sample & 7 year sample & & & & \\
\hline \multirow[t]{2}{*}{ yearmovem1 $(\mathrm{M}-1)$} & $-0.489 * * *$ & $-0.454 * * *$ & -0.00981 & 0.0208 & -0.103 & -0.227 \\
\hline & -0.0762 & -0.111 & -0.0543 & -0.0795 & -0.149 & -0.213 \\
\hline \multirow[t]{2}{*}{ yearmove0 (M0) } & $0.777 * * *$ & $1.016^{* * *}$ & 0.0576 & 0.126 & -0.0346 & 0.0223 \\
\hline & -0.0973 & -0.128 & -0.068 & -0.096 & -0.19 & -0.268 \\
\hline \multirow[t]{2}{*}{ yearmove1 (M1) } & $0.448 * * *$ & $0.709 * * *$ & $-0.145^{*}$ & -0.12 & -0.058 & -0.0421 \\
\hline & -0.107 & -0.131 & -0.0766 & -0.101 & -0.218 & -0.296 \\
\hline \multirow[t]{2}{*}{ yearmove2 (M2) } & $0.338 * * *$ & $0.550 * * *$ & $-0.219 * *$ & -0.167 & 0.0549 & -0.05 \\
\hline & -0.116 & -0.141 & -0.0869 & -0.112 & -0.253 & -0.309 \\
\hline \multirow[t]{2}{*}{ yearmove3 (M3) } & & $0.509 * * *$ & & -0.0881 & & -0.14 \\
\hline & & -0.135 & & -0.121 & & -0.323 \\
\hline \multirow[t]{2}{*}{ yearmove4 (M4) } & & $0.482 * * *$ & & $-0.242 *$ & & -0.287 \\
\hline & & -0.146 & & -0.128 & & -0.358 \\
\hline Observations & 2531 & 2249 & 2527 & 2244 & 2818 & 2578 \\
\hline R-squared & 0.319 & 0.299 & 0.064 & 0.072 & 0.035 & 0.058 \\
\hline Number of pid & 831 & 613 & 831 & 613 & 833 & 614 \\
\hline
\end{tabular}

$p$ value $*<0.1 ; * *<0.05 ; * * *<0.01$

move upward attrition bias. Nevertheless, when samples were limited to individuals who had stayed in their pre/post move accommodation for all the years relative to move (7/7 and $5 / 5$ years), the same pattern of results was observed.

In terms of subjective well-being, there is no positive effect of moving to larger accommodation on GHQ or life satisfaction for either sample. This holds true even when we split the 5 year sample according to gender (see "Appendix 4"). In fact, when the 5 year sample is used, there is a significant negative effect of moving to larger accommodation on life satisfaction 2-3 years after the move.

In summary, moving to larger accommodation leads to an increase in housing satisfaction that is partially sustained over the 5 years post-move. However, consistent with the findings of Nakazato et al. (2011) in Germany, this does not translate into an increase in subjective well-being. 


\section{Discussion and Conclusion}

\subsection{Housing Satisfaction}

Part one showed that space has a positive and diminishing marginal effect on housing satisfaction for both males and females. This implies that pathway one drives the relationship between space and housing satisfaction. Part two suggests that any positive effect of space on housing satisfaction partially diminishes over time. This could be attributed to distinction bias-space becomes a less salient feature of the accommodation; or aspiration spiral theory - the respondent consciously escalates their space aspirations. Either way, these findings have potentially significant implications for our understanding of the housing market. In 2008, 8 \% of BHPS respondents moved for "larger accommodation". Because housing satisfaction is very influential in determining moving propensities (DiazSerrano and Stoyanova 2010), it could be argued that in addition to micro and macro factors, adaptation in housing satisfaction judgements acts to accelerate movement up the housing ladder and increases levels of residential mobility.

\subsection{Subjective Well-Being}

Despite finding large increases in housing satisfaction, part two found no positive effect of moving to larger accommodation on subjective well-being. This supports neither the hedonic treadmill theory, nor the global adaptive utility model. It could simply be that the relationship between space and well-being is not strong enough for these moves to result in a significant increase in subjective well-being. On average individuals in the 5 year sample only increased their number of rooms per person by 0.38 . According to part one, this increase would only lead to a very small increase in subjective well-being, which may require a larger sample size to be identified. However, the negative effect on life satisfaction 2-3 years after the move suggests that there are costs associated with moving house that we have not controlled for. Perhaps these offset the benefits associated with moving. The distances moved were small so disruption of social networks is unlikely to be the reason. It could be that the relative unfamiliarity of the new house and immediate neighbourhood results in a loss of identity and ontological security. Alternatively, the relationship between size of living space and subjective well-being may be asymmetrical i.e. decreases in space may lead to decreases in subjective well-being but increases in space may not lead to increases in subjective well-being.

Part one yields the most interesting findings on the relationship between size of living space and subjective well-being. It produces two pieces of evidence to suggest that pathway two (status) drives the relationship between space and subjective well-being, but independently of housing satisfaction.

First, in contrast to the relationship between space and housing satisfaction which is non-linear, the relationship between space and subjective well-being is linear. This implies that space affects housing satisfaction through pathway one- which should have diminishing marginal utility- but affects subjective well-being through pathway two, which we would expect to be more linear.

Second, the relationship between space and well-being is gendered. The existing literature indicates that pathway two should be stronger for men than women. We find that size of living space impacts on the housing satisfaction of both genders similarly, but that it has a (weak) 
positive impact only on the subjective well-being of men. ${ }^{2}$ If pathway two is the dominant (and gendered) driver of the relationship between space and subjective well-being, but operates independently of housing satisfaction, then this would reconcile our findings with the existing literature i.e. it maybe that men recognise the extra values and activities that a large house facilitates by reporting higher housing satisfaction, but not the extra social status that it affords. Perhaps men do not attribute the sense of pride and confidence associated with high status, to the size of their living space. In short, pathway two may be too distal and indirect for men to appreciate the role of house size. Consequently, housing satisfaction may only partially reflect the true relationship between housing and subjective well-being.

If pathway two is the main driver of the relationship between space and subjective wellbeing - and part one only provides suggestive evidence that it is - then this would imply that size of living space is a positional good. Individuals are deriving subjective well-being from having more space than other people, as opposed to having more space in itself. In this case, minimum space standards are unlikely to have much effect on societal well-being in the UK, as what matters is the distribution of living space, rather than absolute levels of living space. As Wilkinson and Pickett (2009) state, "Greater inequality seems to heighten people's social evaluation anxieties by increasing the importance of social status"(pp. 33-34). A more equal distribution of living space could reduce the anxiety of those with relatively low levels of space, and mitigate conspicuous consumption of (green) space that arises from invidious social comparisons (see Frank 2007 for an economist's version of this argument). However, in working towards greater societal well-being, policy makers also ought to recognise that, like well-being, liberty may also be an intrinsic good (see Sen 2009; Chapter 13 for reasoning). Ceteris paribus, a large house which allows a family to eat together is arguably preferable to a small one that does not, even this capability is not exercised. Similarly, policies that infringe on individual liberty like the 'bedroom tax' need to offer significant tangible benefits in terms of societal well-being in order to represent societal progress.

The fixed effects methodology adopted by this paper, together with the rich set of control variables, provides us with the best insight to date into the causal relationship between size of living space and subjective well-being. However, there remains a risk of reverse causality: males may become happier and therefore buy a larger house (or build an extension), rather than the reverse relationship as we have proposed. Future research could resolve this issue by looking for cases where individuals are randomly assigned increases (or decreases) in living space. Even if the endogeneity issue is resolved, however, it will still be unclear which pathway is dominant in the relationship between space and subjective well-being. Our evidence suggests pathway two but future research should explicitly test for these pathways. Research on the effect of relative income on subjective well-being provides a good starting point. Ferrer-i-Carbonell (2005) and Luttmer (2004) have both used panel data to look at how 'relevant others" income affects individual subjective well-being. If pathway two exists then a man's subjective well-being should depend not only on how much space he has, but also how much space 'relevant others' have.

Due to its exploratory nature, this paper raises many questions for future research. If a large component of the relationship between housing and subjective well-being operates independently of housing satisfaction judgements, as our findings suggest, then where is the value in measuring housing satisfaction? Future psychological research should address this issue by

\footnotetext{
${ }^{2}$ It could be argued that only men benefit from increases in living space, because it is mostly men who make the decision to increase their living space, while women must simply follow. However, in this case, we would expect more men than women to report a shortage of space in the year prior to moving to larger accommodation. In fact, in the part two 5 year sample, a higher proportion of women $(70 \%)$ stated a shortage of space in $\mathrm{M}-1$, than men $(64 \%)$.
} 
looking at the effect of housing factors on housing satisfaction and subjective well-being, respectively. This paper has also limited its scope to adults. The effect of space on children (through educational performance and status) may be stronger, and apply across both genders (Solari and Mare 2012). Moreover, this paper has only looked at well-being at the individual level. Future research should examine well-being at the collective/household level, where interactions between the different actors in the household are likely to moderate the relationship (Hagan et al. 1996). The relationship should also be explored in other cultural contexts. In more collectivistic and equal countries, housing maybe less of a status symbol, and pathway one may be more dominant in determining subjective well-being.

This paper does not purport to provide definitive answers to all the topical and complex issues surrounding the relationship between size of living space and subjective well-being, but hopefully does provide a useful platform for further empirical research.

Acknowledgments I am enormously grateful to David Clapham, Tommaso Gabrieli and Sarah Jewell for their guidance thoughout. I thank the various anonymous referees for their clear comments which greatly improved the paper in terms of structure and methodology. Finally, a word of thanks must go to Alec Foye for making the paper more concise and altogether more readable.

Open Access This article is distributed under the terms of the Creative Commons Attribution 4.0 International License (http://creativecommons.org/licenses/by/4.0/), which permits unrestricted use, distribution, and reproduction in any medium, provided you give appropriate credit to the original author(s) and the source, provide a link to the Creative Commons license, and indicate if changes were made.

\section{Appendix 1}

See Table 4.

Table 4 Variable coding

\begin{tabular}{|c|c|}
\hline Variable & Description \\
\hline \multicolumn{2}{|c|}{ General variables that could potentially influence $S W B$} \\
\hline child_0_2 & $1=$ Child in household $0-2$ years old; $0=$ otherwise \\
\hline child_3_4 & $1=$ Child in household $3-4$ years old; $0=$ otherwise \\
\hline \multicolumn{2}{|c|}{$\begin{array}{l}\text { child _5_11; child_12_15; child_ } 16 \_18 \text { all work in same way: } 1=\text { Child in household in age group; } \\
0=\text { otherwise }\end{array}$} \\
\hline kids_total & Number of children in household \\
\hline log_hh_income & Log of household income \\
\hline log_ind_income & Log of individual income \\
\hline winter & $1=$ survey conducted in Nov/Dec/Jan/Feb; $0=$ otherwise \\
\hline married & $1=$ married; $0=$ otherwise \\
\hline cohabiting & $1=$ cohabiting $; 0=$ otherwise \\
\hline widowed & $1=$ widowed $0=$ otherwise \\
\hline div_sep & $1=$ divorced or separated; $0=$ otherwise \\
\hline smoker & $1=$ smokes $; 0=$ otherwise \\
\hline Household size & Number of people in household \\
\hline resi_carer & $1=$ cares for someone in household; $0=$ otherwise \\
\hline non_resi_carer & $1=$ cares for someone outside of household; $0=$ otherwise \\
\hline frequency_meeting_people & $\begin{array}{l}1=\text { if meets people at least once or twice per month; } 0=\text { if meets people less } \\
\text { than once per month }\end{array}$ \\
\hline
\end{tabular}


Table 4 continued

\begin{tabular}{|c|c|}
\hline Variable & Description \\
\hline retired & $1=$ Retired; $0=$ otherwise \\
\hline student & $1=$ FT student $0=$ otherwise \\
\hline age & Age at time of interview* \\
\hline employed & $1=$ employed $0=$ otherwise \\
\hline poor_health & $1=$ Health status poor/very poor over last 12 months; $0=$ otherwise \\
\hline yr1991; yr1992; ..;yr2008 & $1=$ Observed in that particular year; $0=$ otherwise \\
\hline \multicolumn{2}{|c|}{ Housing and environmental variables } \\
\hline detached & $1=$ Detached house; $0=$ Otherwise \\
\hline terraced & $1=$ Terrace House $; 0=$ Otherwise \\
\hline semi Detached & $1=$ Semi detached house $; 0=$ Otherwise \\
\hline flat & $1=$ Flat; $0=$ Otherwise \\
\hline sheltered & $1=$ Sheltered Accommodation; $0=$ Otherwise \\
\hline owner & $1=$ Owner-occupier, outright; $0=$ otherwise \\
\hline public & $1=$ LA or HA owned home; $0=$ otherwise \\
\hline private & $1=$ Private rental property $0=$ otherwise \\
\hline street_noise & $1=$ if reports neighbour street problem; $0=$ otherwise \\
\hline neighbour_noise & $1=$ if reports neighbour noise problem; $0=$ otherwise \\
\hline vandalism & $1=$ if reports vandalism problems; $0=$ otherwise \\
\hline pollution & $1=$ if reports local area pollution problems; $0=$ otherwise \\
\hline no_light & $1=$ if reports poor lighting; $0=$ otherwise \\
\hline Rot & $1=$ if home has rot; $0=$ otherwise \\
\hline condensation & $1=$ if reports condensation; $0=$ otherwise \\
\hline Leaky roof & $1=$ if roof has leaks; $0=$ otherwise \\
\hline poor_heating & $1=$ if reports heating problem; $0=$ otherwise \\
\hline Garden & $1=$ has garden; $0=$ otherwise \\
\hline rooms_pp & $\begin{array}{l}\text { Number of rooms per person }=\text { number of rooms/number of people in } \\
\text { household* }\end{array}$ \\
\hline damp_walls & $1=$ if home has damp; $0=$ otherwise \\
\hline \multicolumn{2}{|c|}{ Potential "costs"(in terms of well-being) associated with larger accommodation } \\
\hline mover & $1=$ Moved house in previous year; $0=$ otherwise $^{*}$ \\
\hline housework & Hours spent doing housework \\
\hline commute_time & $\begin{array}{l}\text { Number of minutes spent commuting to work (self employed and employed } \\
\text { responses merged). If N/A, commute time }=0\end{array}$ \\
\hline housing_costs & Net Monthly Housing Costs \\
\hline house_value & House Value; $0=$ if renting public or private \\
\hline \multicolumn{2}{|c|}{ 'Neighbourhood Effects'-indices of deprivation at the lower level SOA in 2004 (ODPM 2004) } \\
\hline Health_Disab_Score & Health Deprivation and Disability Score \\
\hline Education_Score & Education, Skills and Training Score \\
\hline Income_Score & Income Score \\
\hline Housing_Services_Score & Barriers to Housing and Services Score* \\
\hline Crime_Score & Crime Score* \\
\hline Living_Env_Score & Living Environment Score* \\
\hline Multi_Dep_Score & Multiple Deprivation Score \\
\hline
\end{tabular}

* Only included in part one regressions 


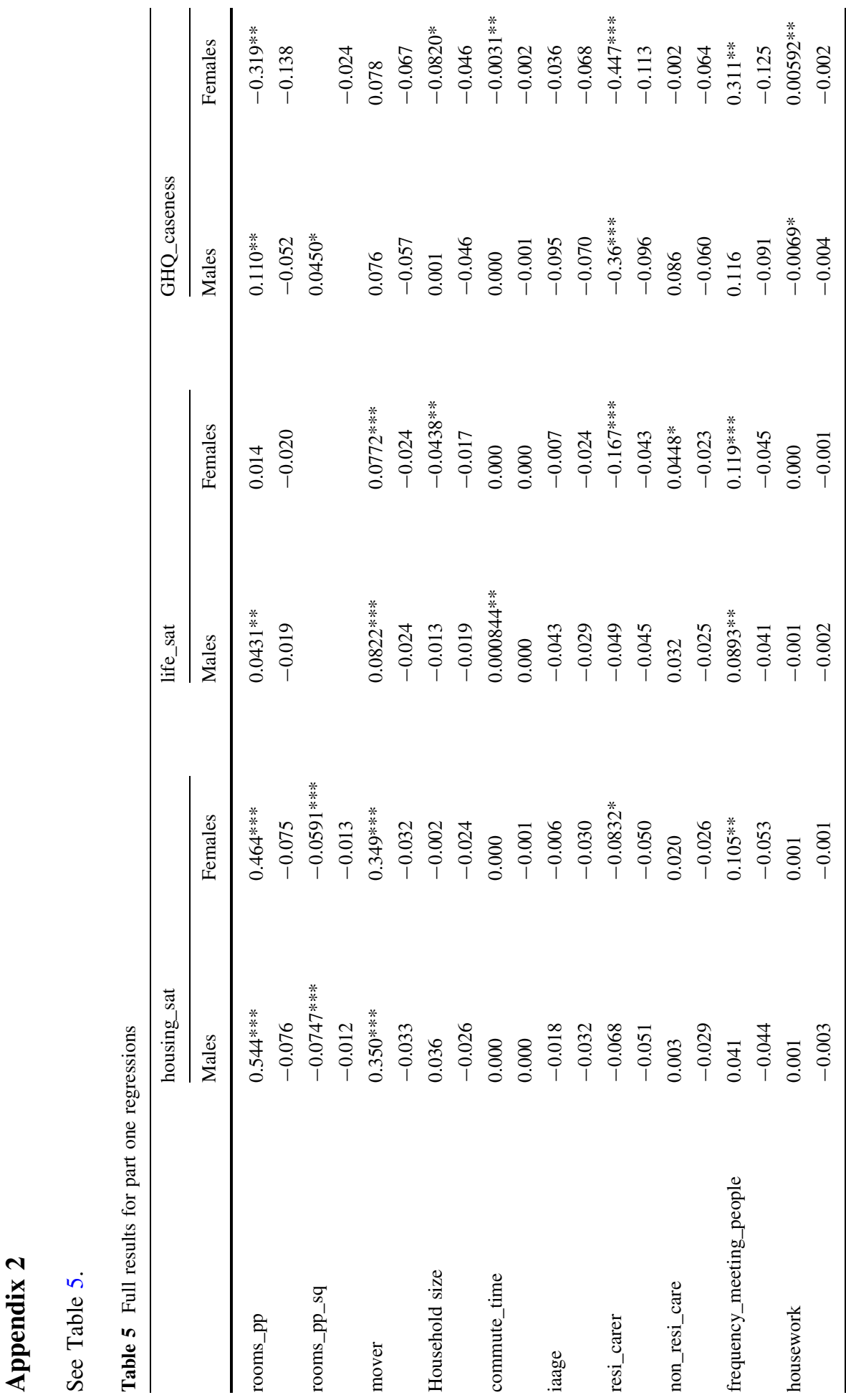




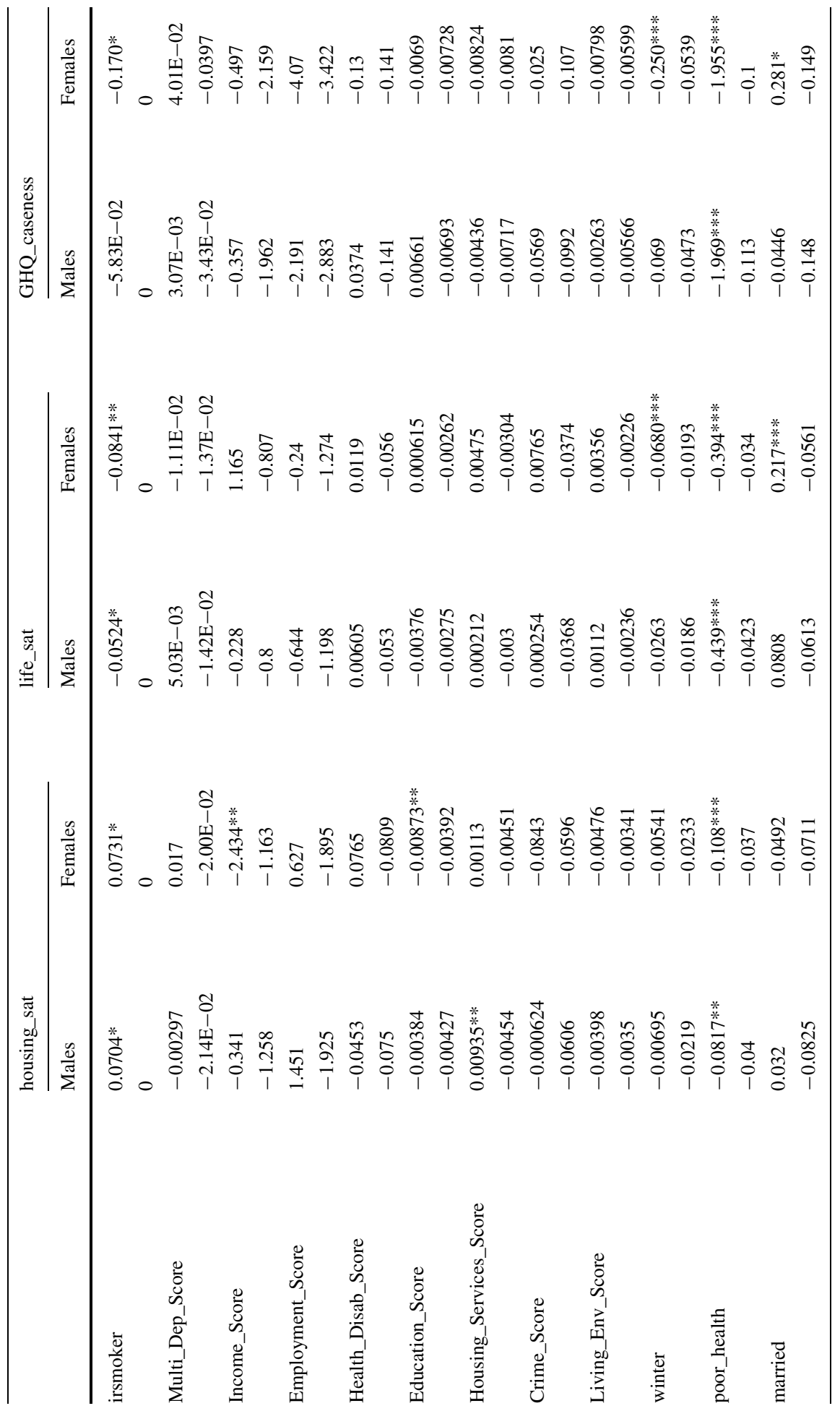




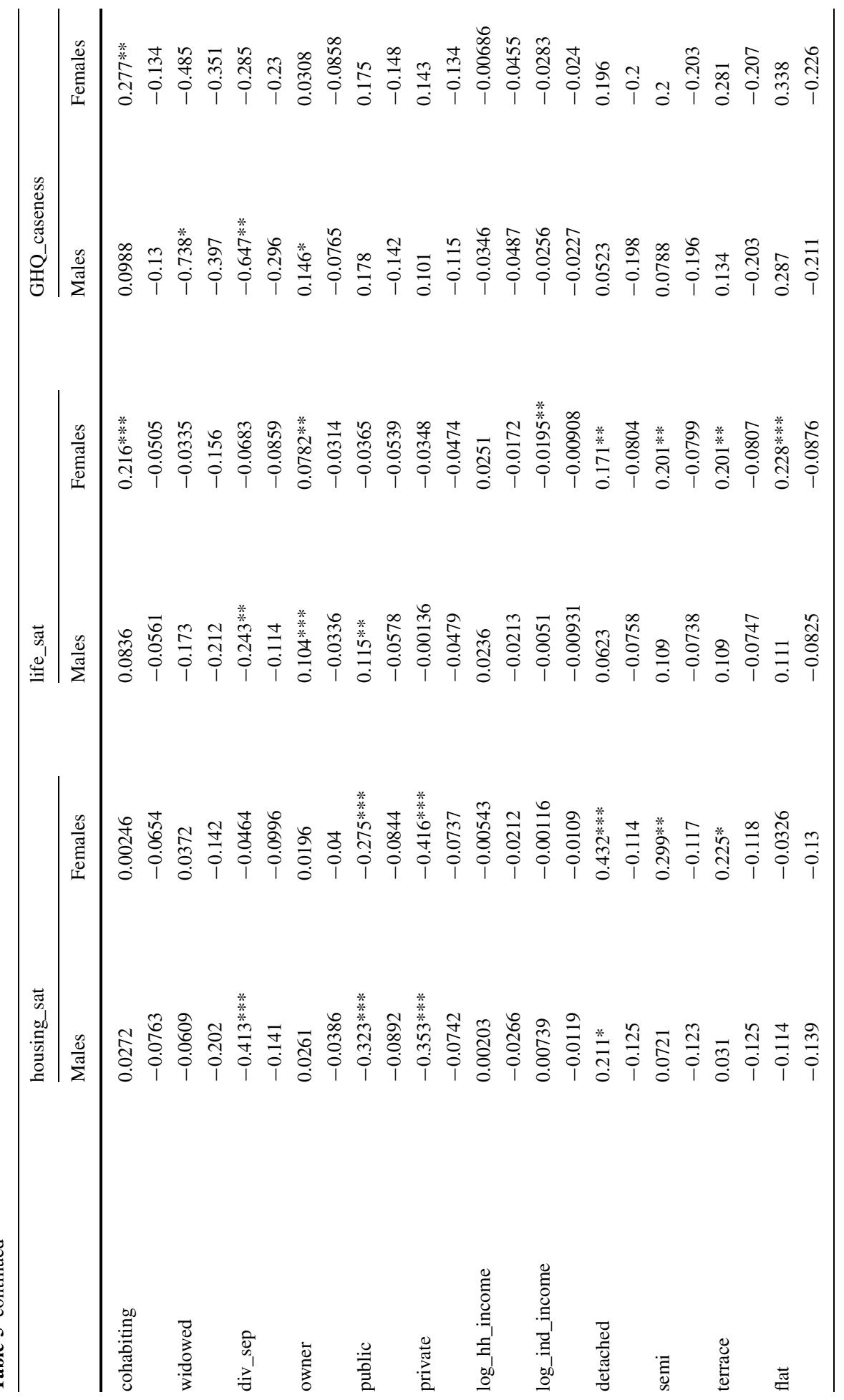




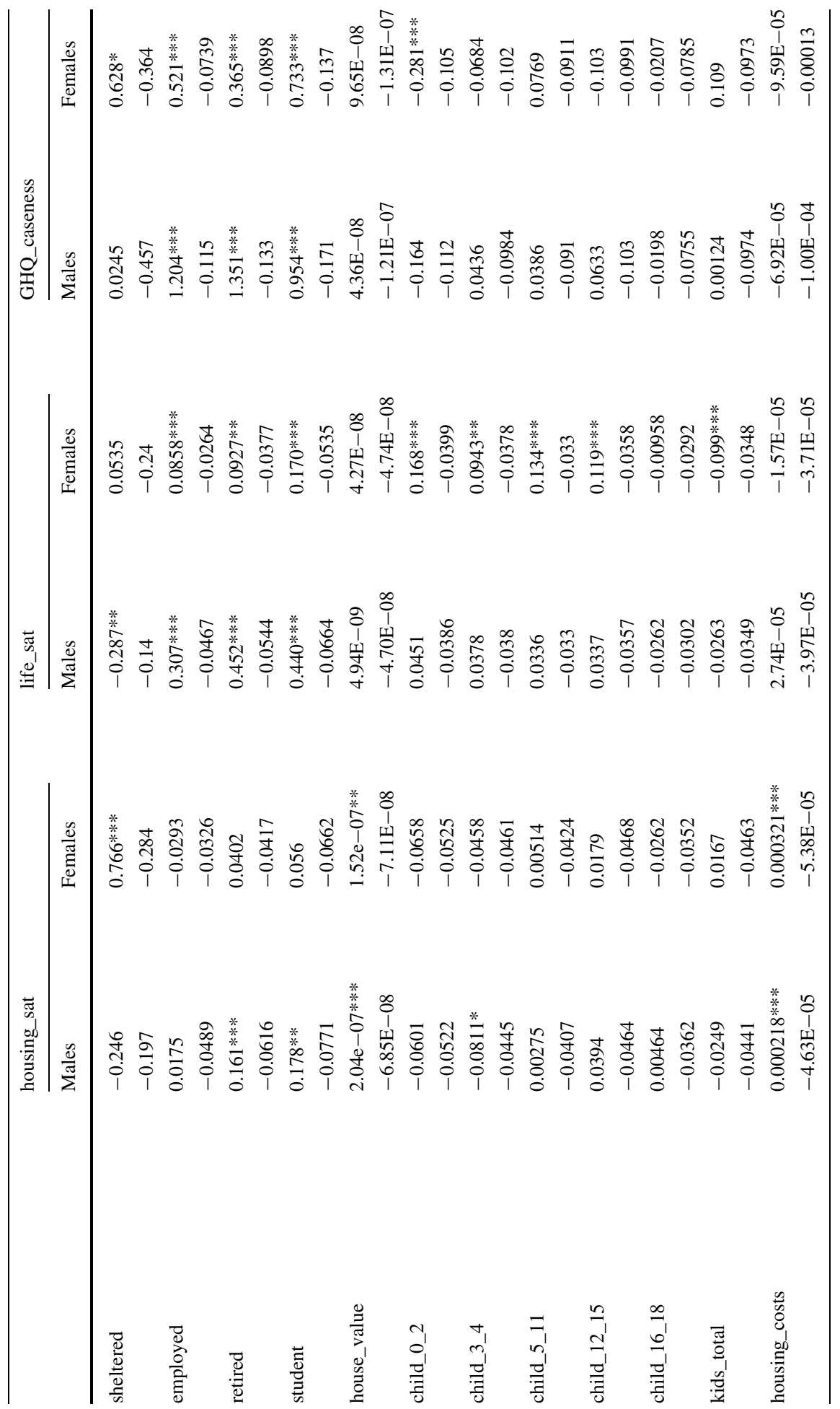




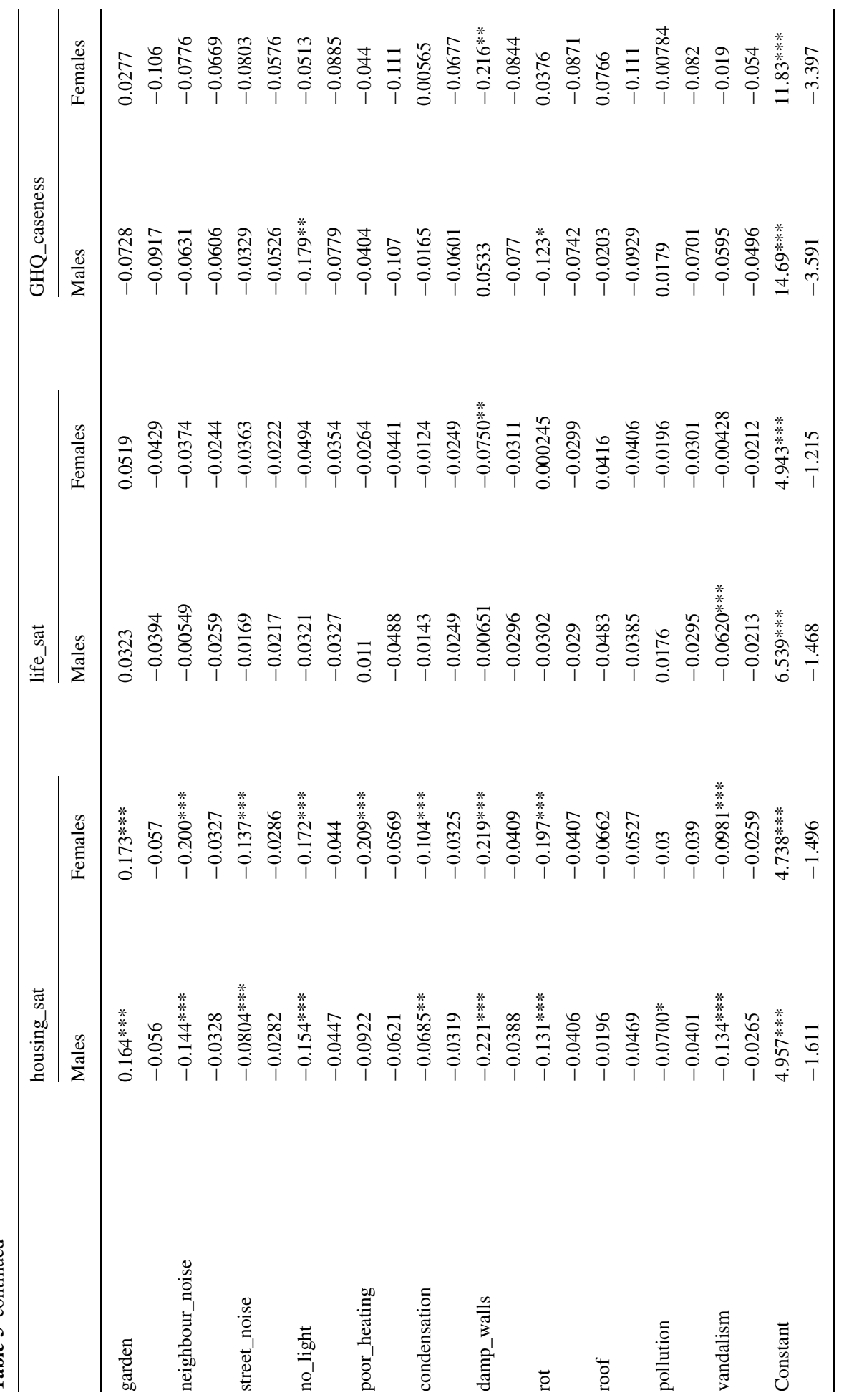




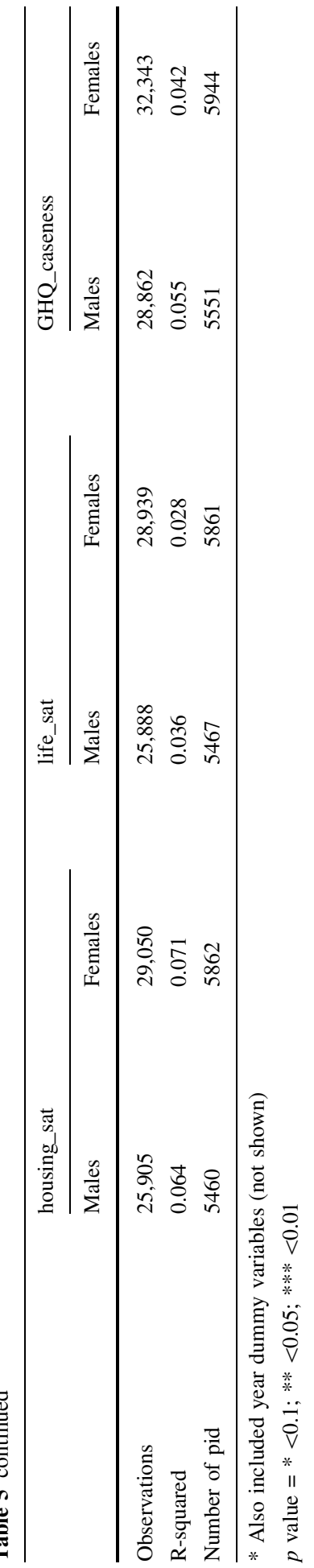




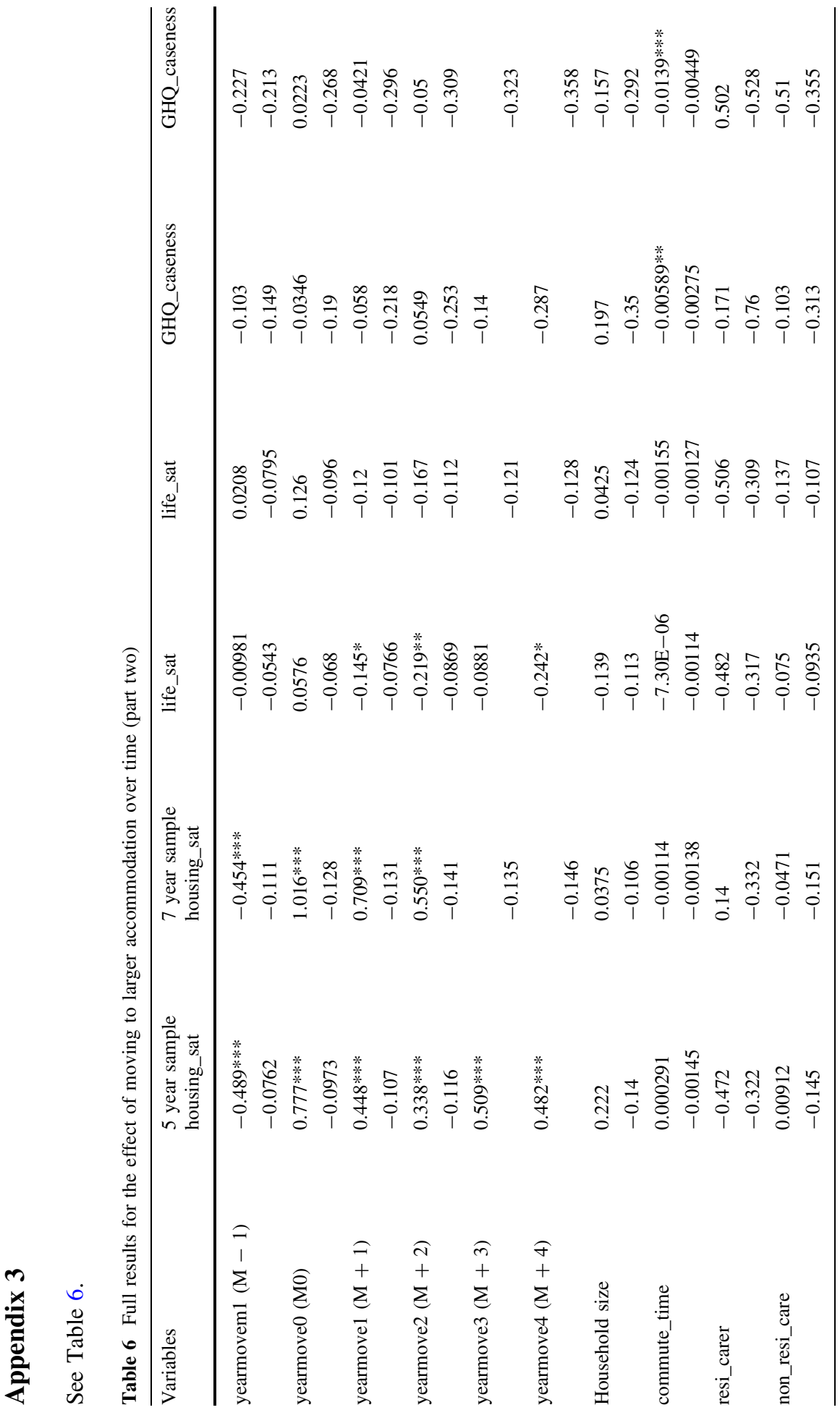




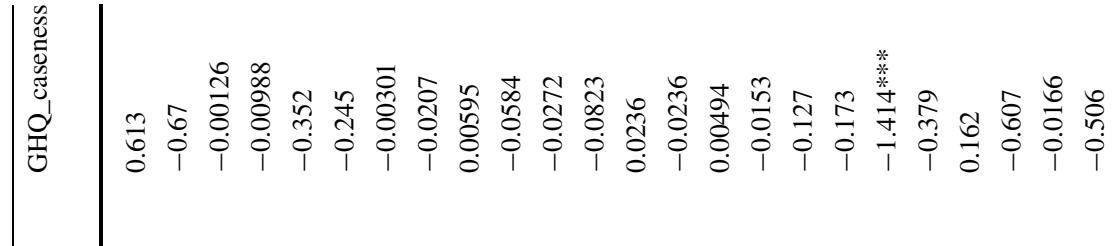

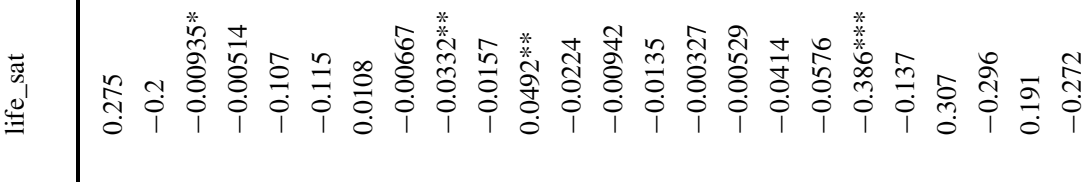

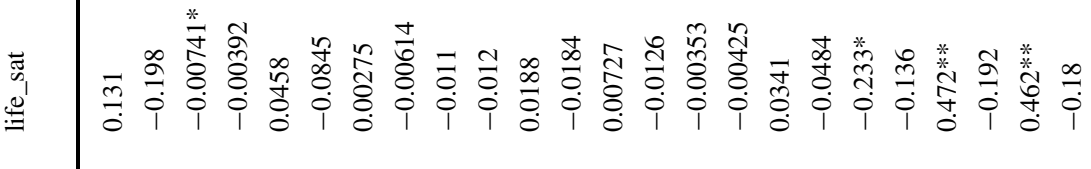

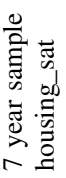

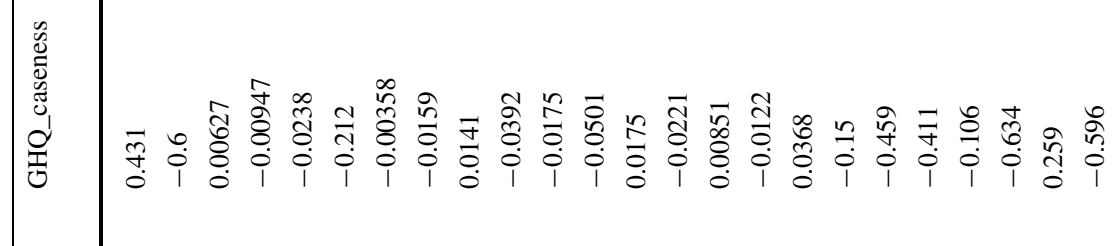

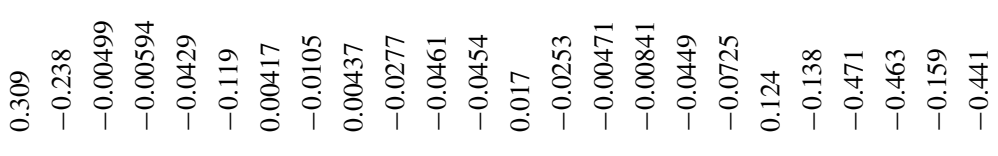

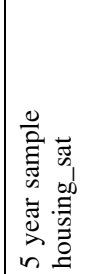

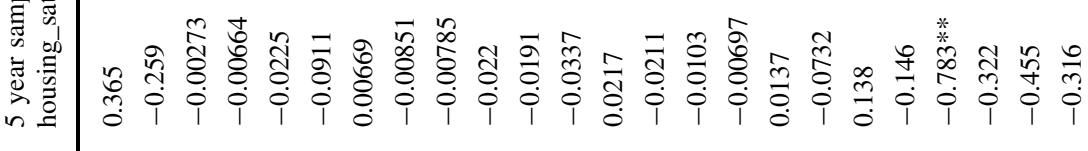

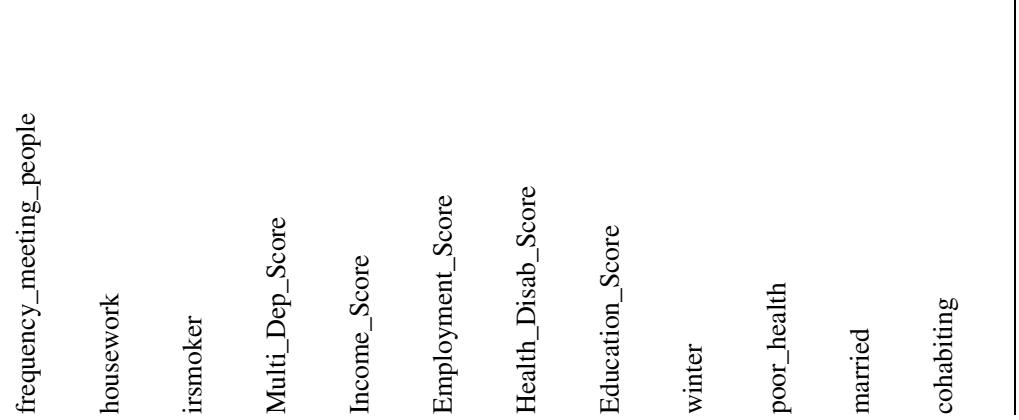




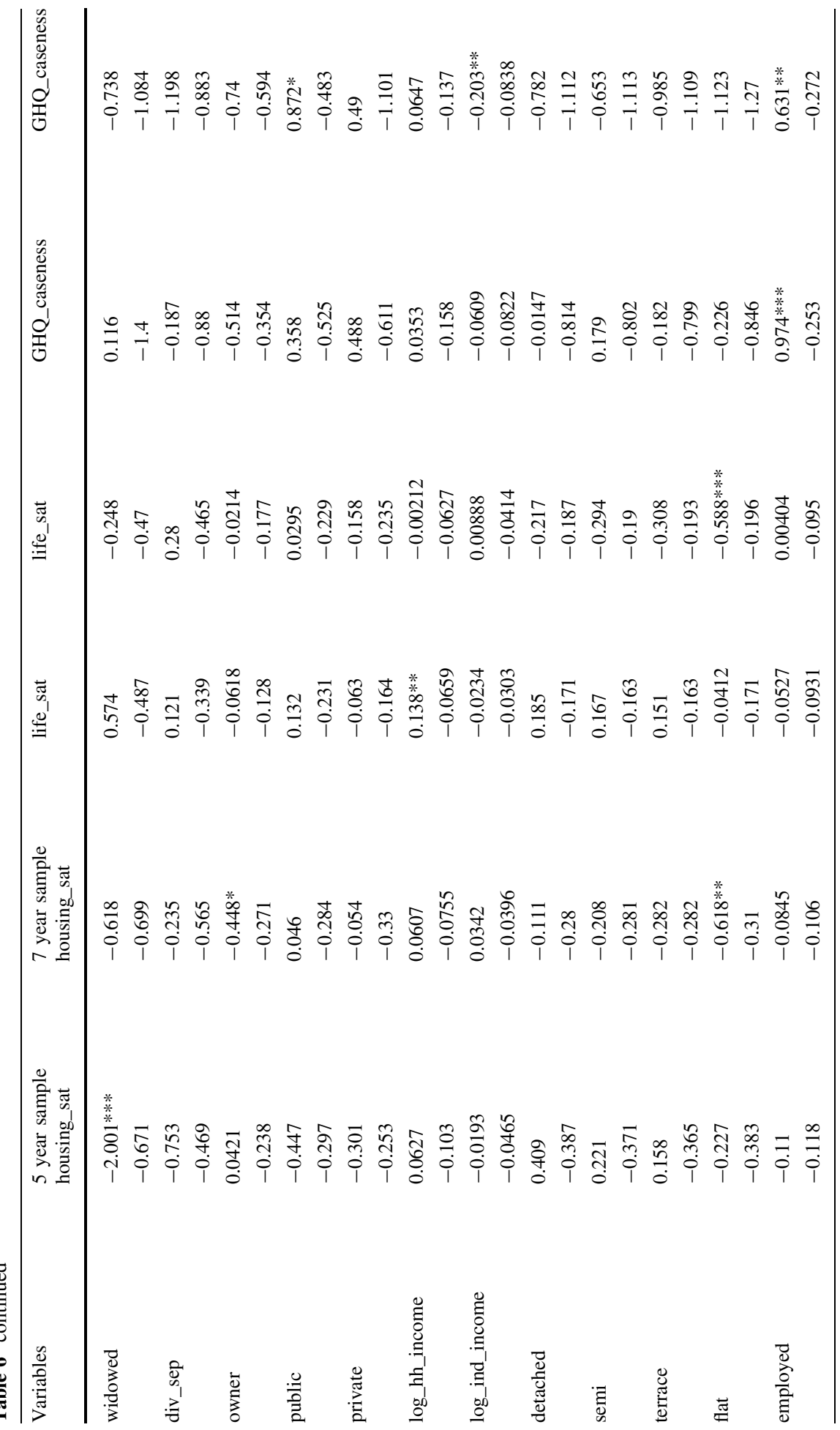




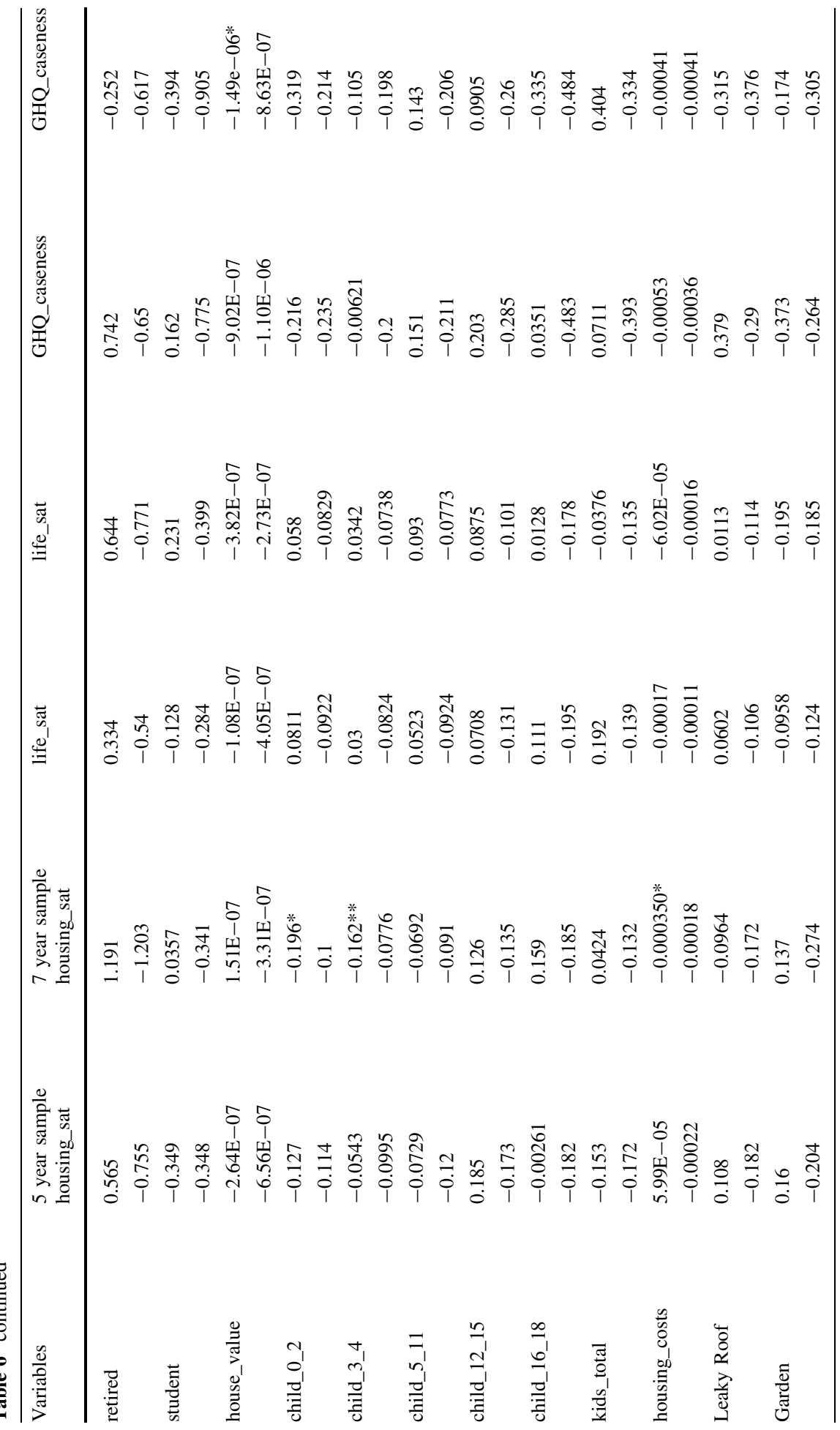




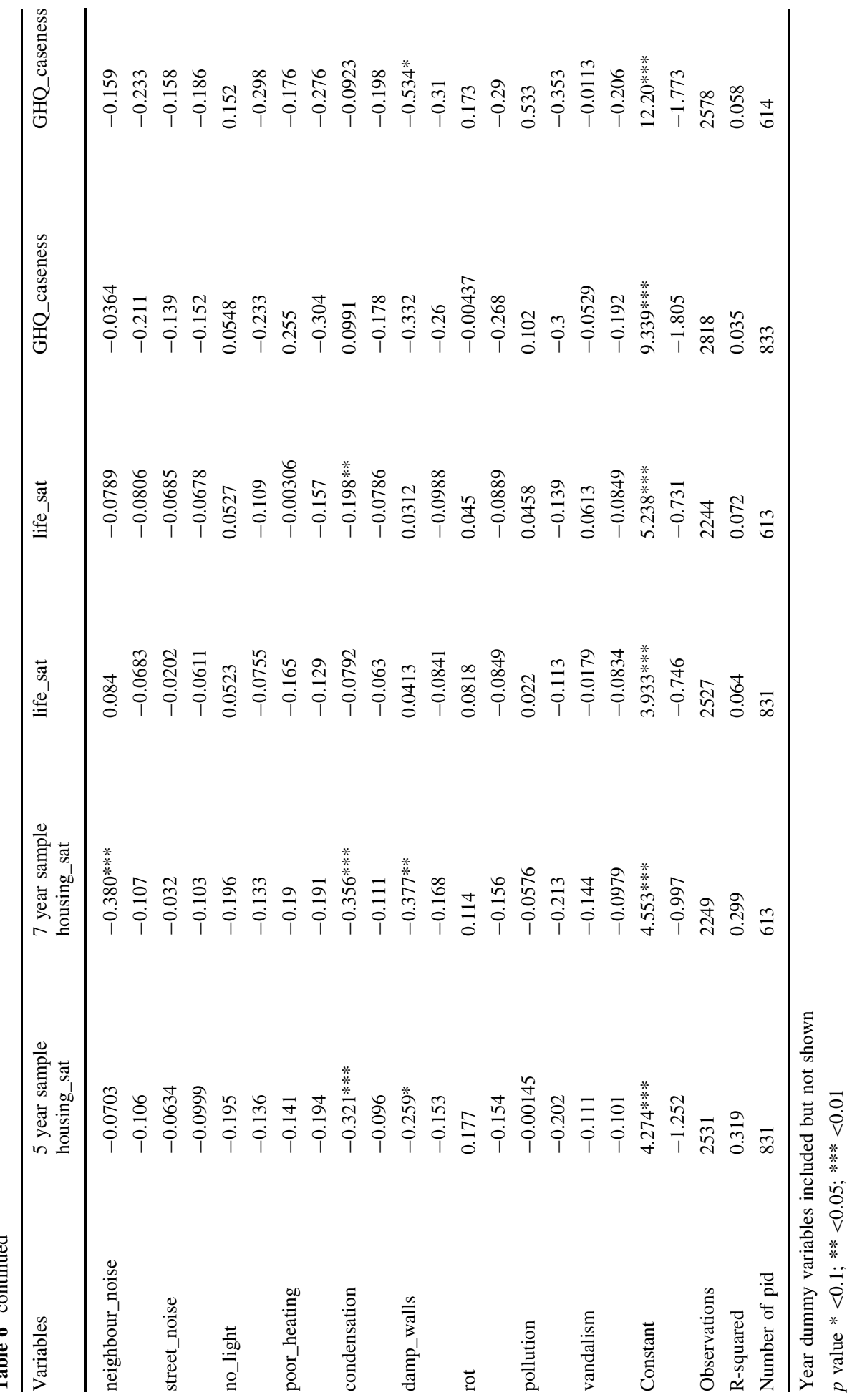




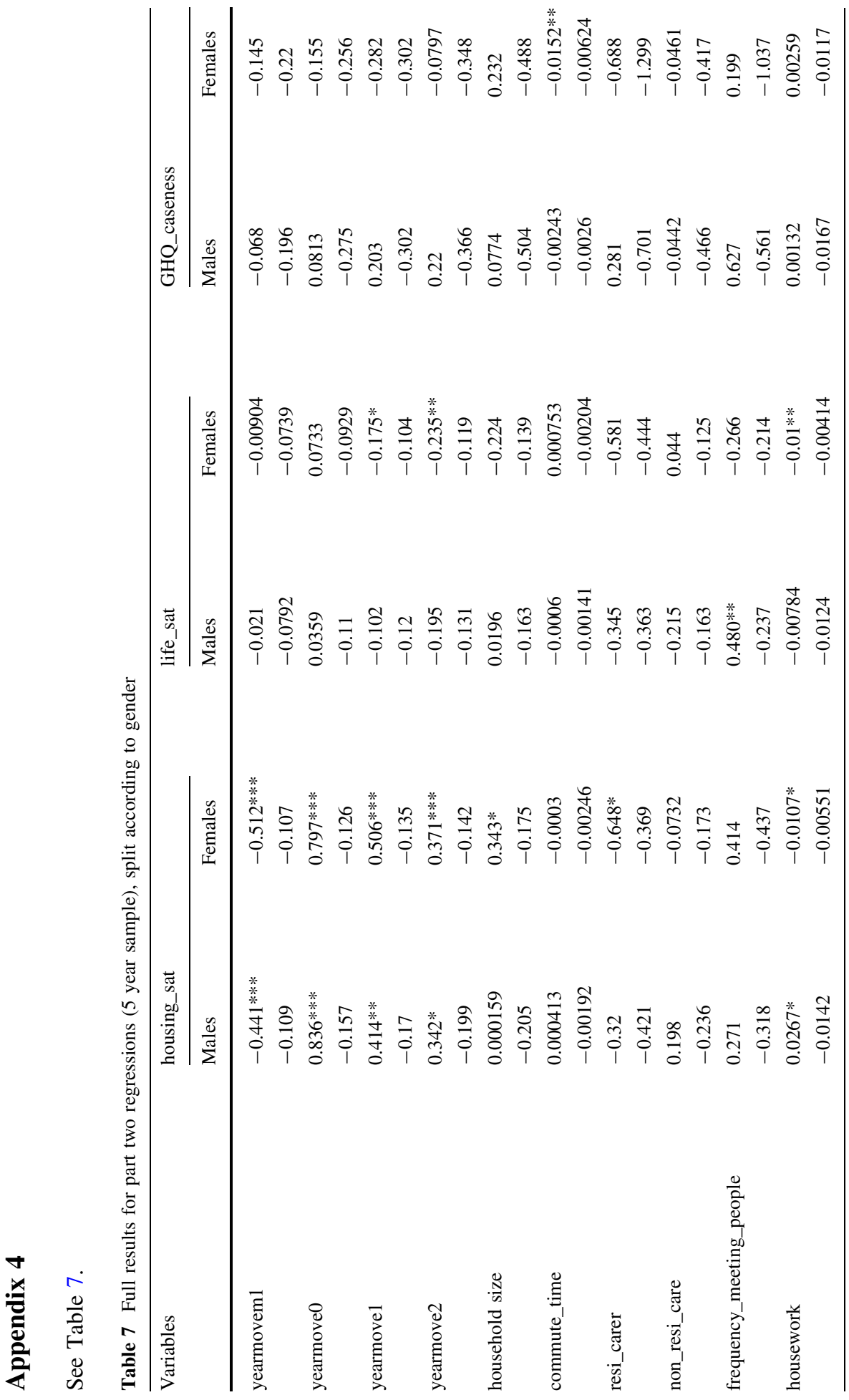




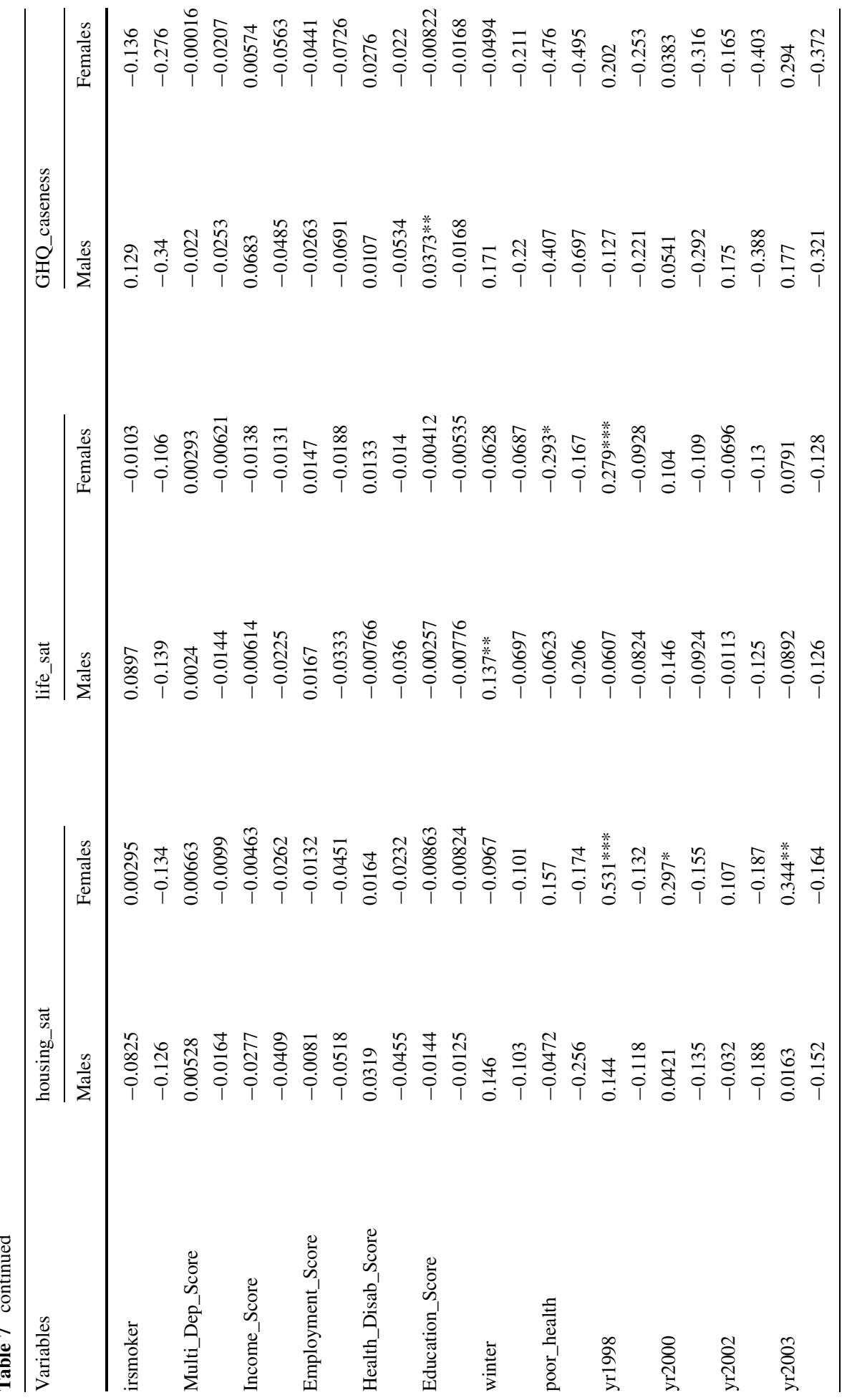




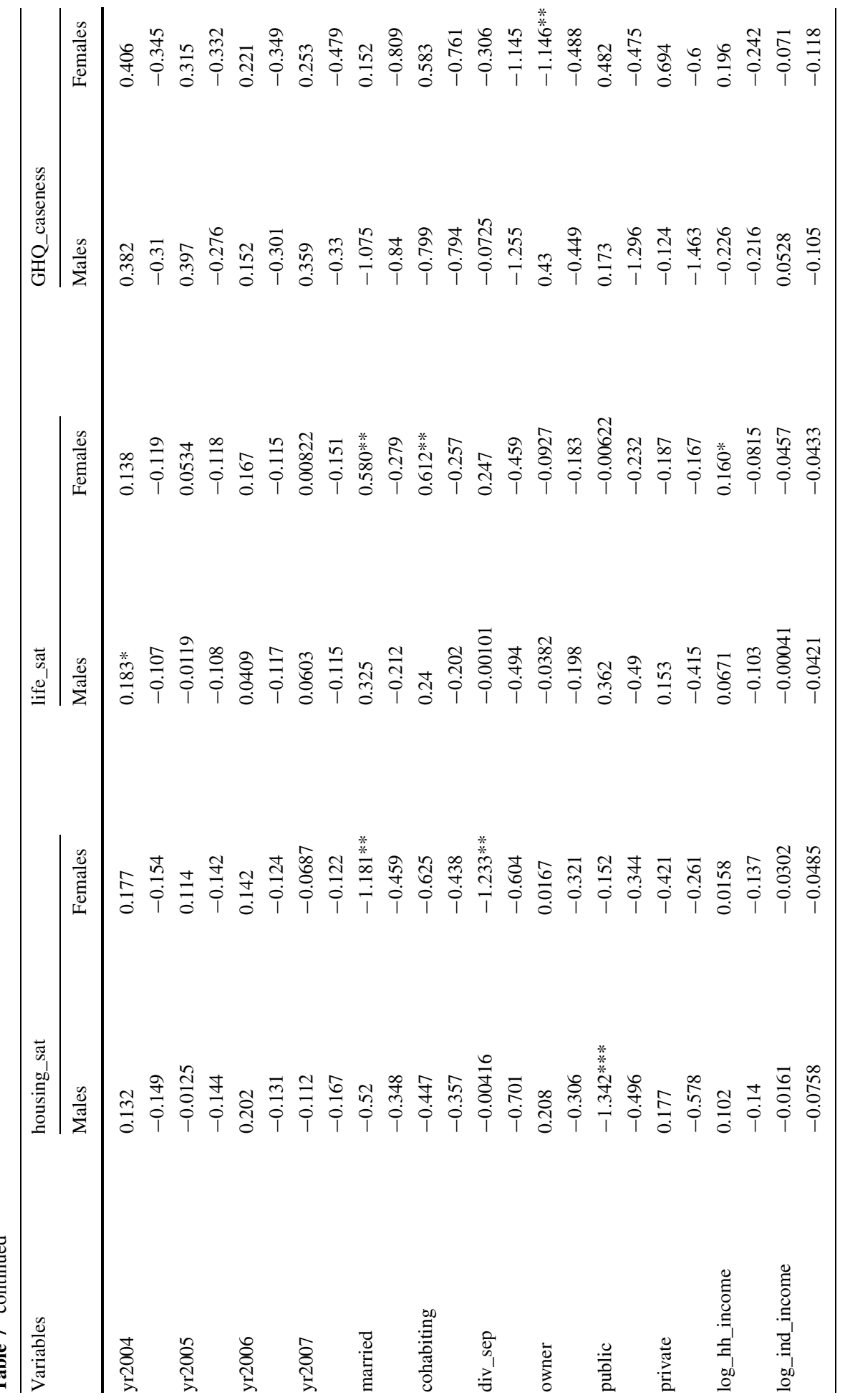




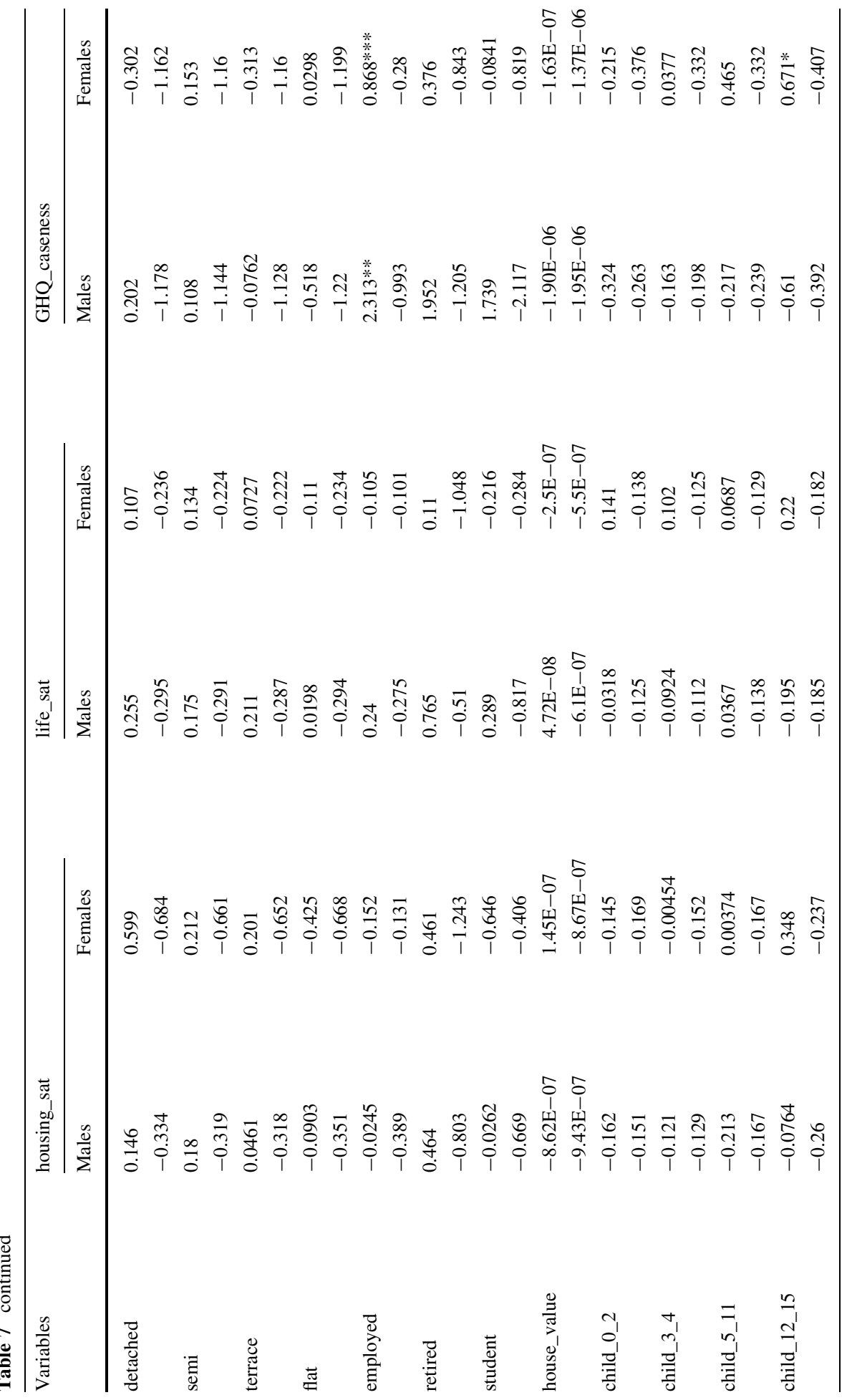




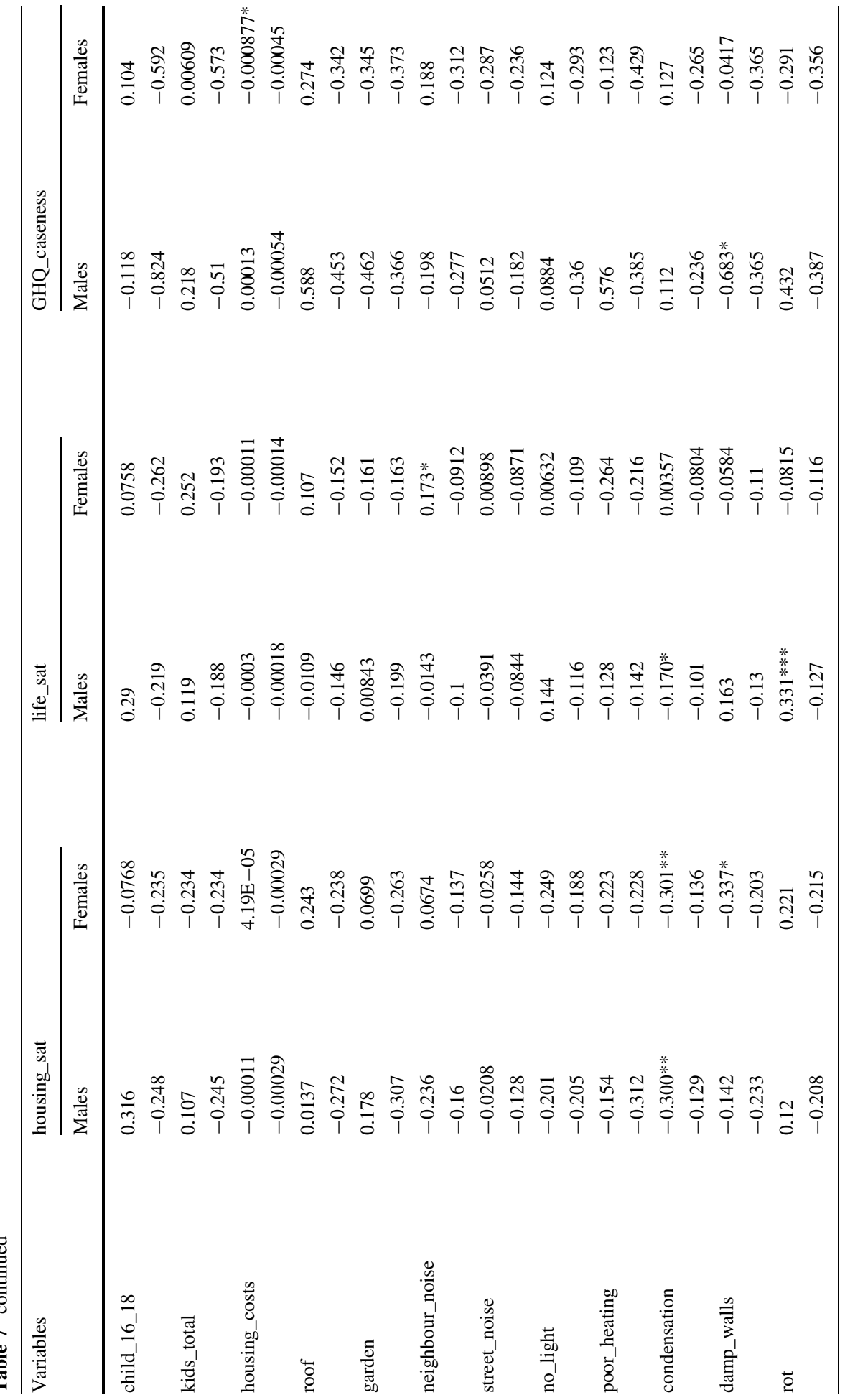




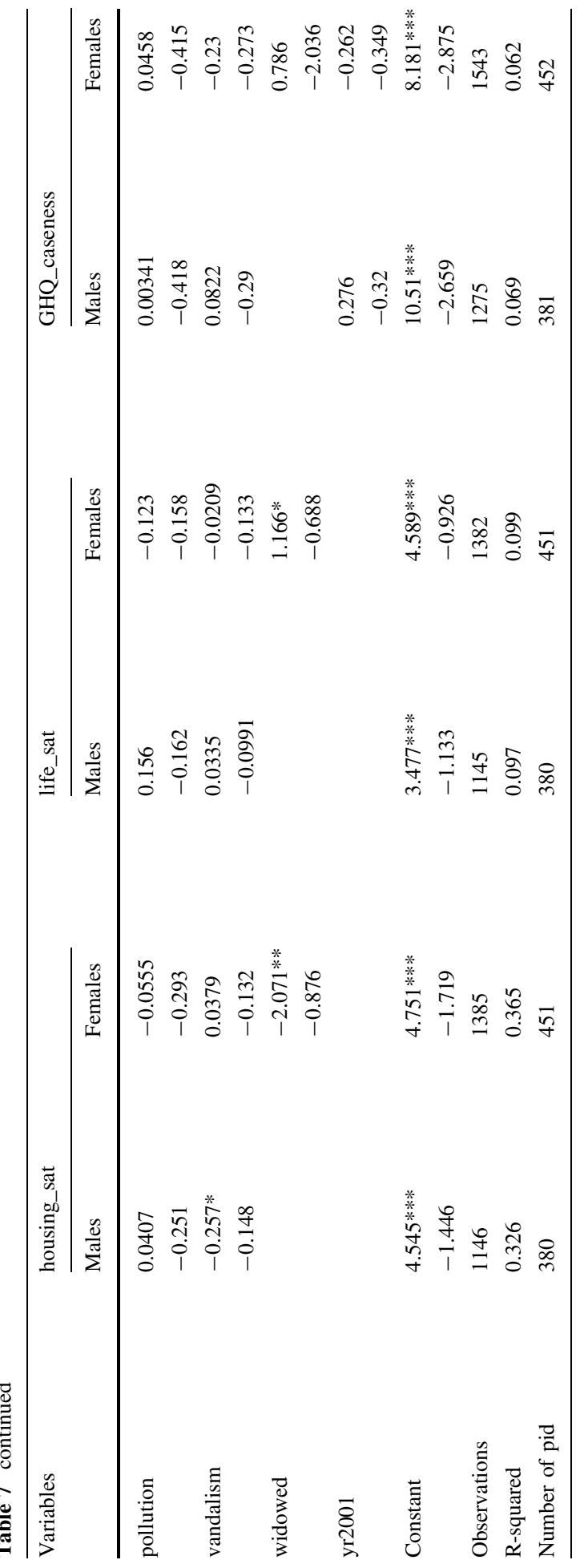




\section{References}

Bradford, W. D., \& Dolan, P. (2010). Getting used to it: The adaptive global utility model. Journal of Health economics, 29(6), 811-820.

Carlson, R. (1971). Sex differences in ego functioning: Exploratory studies of agency and communion. Journal of Consulting and Clinical Psychology, 37(2), 267-277.

Clark, A. E. (2003). Unemployment as a social norm: Psychological evidence from panel data. Journal of Labor Economics, 21(2), 323-351.

Clark, A. E., Diener, E., Georgellis, Y., \& Lucas, R. E. (2008). Lags and leads in life satisfaction: A test of the baseline hypothesis*. The Economic Journal, 118(529), F222-F243.

Clark, A. E., \& Georgellis, Y. (2013). Back to baseline in Britain: Adaptation in the British household panel survey. Economica, 80(319), 496-512.

Clark, A., Knabe, A., \& Rätzel, S. (2010). Boon or bane? Others' unemployment, subjective well-being and job insecurity. Labour Economics, 17(1), 52-61.

Csikszentmihalyi, M., \& Halton, E. (1981). The meaning of things: Domestic symbols and the self. Cambridge: Cambridge University Press.

Diaz-Serrano, L., \& Stoyanova, A. P. (2010). Mobility and housing satisfaction: An empirical analysis for 12 EU countries. Journal of Economic Geography, 10(5), 661-683.

Diener, E., Inglehart, R., \& Tay, L. (2013). Theory and validity of life satisfaction scales. Social Indicators Research, 112(3), 497-527.

Diener, E., Lucas, R. E., \& Scollon, C. N. (2006). Beyond the hedonic treadmill: Revising the adaptation theory of well-being. American Psychologist, 61(4), 305.

Dorling, D. (2014). All that is solid: How the great housing disaster defines our times, and what we can do about it. London: Penguin UK.

Eurofound (2012). Third European Quality of Life Survey-Quality of life in Europe: Impacts of the crisis. Available Online at http://www.eurofound.europa.eu/publications/report/2012/quality-of-life-socialpolicies/quality-of-life-in-europe-impacts-of-the-crisis.

Evans, A. W. (1991). 'Rabbit Hutches on Postage Stamps': Planning. Development and Political Economy. Urban studies, 28(6), 853-870.

Evans, A., \& Hartwich, O. (2005). Unaffordable housing. Policy Exchange, 5, 21-36.

Ferrer-i-Carbonell, A. (2005). Income and well-being: An empirical analysis of the comparison income effect. Journal of Public Economics, 89(5), 997-1019.

Findlay, A. M., \& Nowok, B. (2012). The uneven impact of different life domains on the wellbeing of migrants. CPC Working Papers.

Frank, R. (2007). Falling behind: How rising inequality harms the middle class (Vol. 4). University of California Press.

Frijters, P. (2000). Do individuals try to maximize general satisfaction? Journal of Economic Psychology, 21(3), 281-304.

Frijters, P., Johnston, D. W., \& Shields, M. A. (2011). Life satisfaction dynamics with quarterly life event data. The Scandinavian Journal of Economics, 113(1), 190-211.

Fujiwara, D. (2014). The social impact of housing providers. London: HACT, Legal \& General, Plus Dane Group.

Galster, G. C., \& Hesser, G. W. (1981). Residential satisfaction compositional and contextual correlates. Environment and Behavior, 13(6), 735-758.

Gutmann, D. L. (1965). Women and the conception of ego strength. Merrill-Palmer Quarterly of Behavior and Development, 11(3), 229-240.

Hagan, J., MacMillan, R., \& Wheaton, B. (1996). New kid in town: Social capital and the life course effects of family migration on children. American Sociological Review, 61(3), 368-385.

Haisken-DeNew, John P., \& Hahn, Markus. (2010). PanelWhiz: Efficient data extraction of complex panel data sets: An example using the german SOEP. Journal of Applied Social Science Studies, 130(4), 643-654.

Hirsch, F. (2005). Social limits to growth. London: Routledge.

Hsee, C. K., \& Zhang, J. (2004). Distinction bias: Misprediction and mischoice due to joint evaluation. Journal of Personality and Social Psychology, 86(5), 680.

Jansen, S. J. (2014). Why is housing always satisfactory? A study into the impact of cognitive restructuring and future perspectives on housing appreciation. Social Indicators Research, 116(2), 353-371.

Layard, R. (2005). Happiness: Lessons form a New science. London: Allen Lane.

Luttmer, E. F. (2004). Neighbours as negatives: Relative earnings and well-being (No. w10667). National Bureau of Economic Research.

Marx, K., \& Engels, F. (1965). The German ideology (1845). London. 
Mayraz, G., Wagner, G., \& Schupp, J. (2009). Life satisfaction and relative income: Perceptions and evidence. CEP Discussion Paper 918, LSE (March).

Naipaul, V. (1991). India. One Million Mutinies Now.

Nakazato, N., Schimmack, U., \& Oishi, S. (2011). Effect of changes in living conditions on subjective wellbeing: A prospective top-down bottom-up model. Social Indicators Research, 100(1), 115-135.

Nowok, B., van Ham, M., Findlay, A. M., \& Gayle, V. (2013). Does migration make you happy? A longitudinal study of internal migration and subjective well-being. Environment and Planning A, 45(4), 986-1002.

OECD. (2011). Better Life Index. Available online at http://www.oecdbetterlifeindex.org/

Office for Deputy Prime Minister. (2004). Information on indices of deprivation 2004 for super output areas. Available at http://www.neighbourhood.statistics.gov.uk/

Pavot, W., \& Diener, E. (1993). Review of the satisfaction with life scale. Psychological Assessment, 5(2), 164.

Pevalin, D. J., Taylor, M. P., \& Todd, J. (2008). The dynamics of unhealthy housing in the UK: A panel data analysis. Housing Studies, 23(5), 679-695.

Rainwater, L. (1966). Fear and the house-as-haven in the lower class. Journal of the American Institute of Planners, 32(1), 23-31.

Reynolds, L. (2005). Full House? How overcrowded housing affects families. London: Shelter.

Robert-Hughes, R. (2011). In W. Fox \& A. Scott- Marshall (Eds.), The case for space: The size of England's new homes. RIBA.

Schimmack, U. (2001). Pleasure, displeasure, and mixed feelings: Are semantic opposites mutually exclusive? Cognition and Emotion, 15, 81-97.

Schimmack, U., Diener, E., \& Oishi, S. (2002a). Life-satisfaction is a momentary judgment and a stable personality characteristic: The use of chronically accessible and stable sources. Journal of Personality, 70, 345-385.

Schimmack, U., Radhakrishnan, P., Oishi, S., Dzokoto, V., \& Ahadi, S. (2002b). Culture, personality, and subjective well-being: Integrating process models of life satisfaction. Journal of Personality and Social Psychology, 82, 582-590.

Seeley, J. R., Loosley, E. W., \& Sim, A. R. (1956). Crestwood heights (p. 366). Toronto: University of Toronto Press.

Sen, A. (1983). Poor, relatively speaking. Oxford Economic Papers, 35(2), 153-169.

Sen, A. (2009). The idea of justice. Cambridge, MA: Harvard University Press.

Shields, M. A., Price, S. W., \& Wooden, M. (2009). Life satisfaction and the economic and social characteristics of neighbourhoods. Journal of Population Economics, 22(2), 421-443.

Solari, C. D., \& Mare, R. D. (2012). Housing crowding effects on children's wellbeing. Social Science Research, 41(2), 464-476.

Stutzer, A. (2004). The role of income aspirations in individual happiness. Journal of Economic Behavior \& Organization, 54(1), 89-109.

Tunstall, B. (2015). Relative housing space inequality in England and Wales, and its recent rapid resurgence. Abingdon: Taylor and Francis.

Van Praag, B. M., Frijters, P., \& Ferrer-i-Carbonell, A. (2003). The anatomy of subjective well-being. Journal of Economic Behavior \& Organization, 51(1), 29-49.

Veblen, T. (1899). The theory of the leisure class. New York: The New American Library.

Vera-Toscano, E., \& Ateca-Amestoy, V. (2008). The relevance of social interactions on Housing Satisfaction. Social Indicators Research, 86(2), 257-274.

Wilkinson, R., \& Pickett, K. (2009). The spirit level: Why greater equality makes societies stronger. London: Bloomsbury Publishing USA.

Wilson, T. D., \& Gilbert, D. T. (2008). Explaining away: A model of affective adaptation. Perspectives on Psychological Science, 3(5), 370-386. 